\title{
Risk Aversion, Investor Information, and Stock Market Volatility
}

\author{
Kevin J. Lansing \\ Federal Reserve Bank of San Francisco \\ Stephen F. LeRoy \\ UC Santa Barbara and \\ Federal Reserve Bank of San Francisco
}

April 2014

Working Paper 2010-24

http://www.frbsf.org/publications/economics/papers/2010/wp10-24bk.pdf

The views in this paper are solely the responsibility of the authors and should not be interpreted as reflecting the views of the Federal Reserve Bank of San Francisco or the Board of Governors of the Federal Reserve System. 


\title{
Risk Aversion, Investor Information and Stock Market Volatility*
}

\author{
Kevin J. Lansing ${ }^{\dagger}$ \\ Federal Reserve Bank of San Francisco
}

Stephen F. LeRoy

UC Santa Barbara and Federal Reserve Bank of San Francisco

April 23, 2014

\begin{abstract}
This paper employs a standard asset pricing model to derive theoretical volatility measures in a setting that allows for varying degrees of investor information about the dividend process. We show that the volatility of the price-dividend ratio increases monotonically with investor information but the relationship between investor information and equity return volatility (or equity premium volatility) can be non-monotonic, depending on risk aversion and other parameter values. Under some plausible calibrations and information assumptions, we show that the model can match the standard deviations of equity market variables in long-run U.S. data. In the absence of concrete knowledge about investors' information, it becomes more difficult to conclude that observed volatility in the data is excessive.
\end{abstract}

Keywords: Asset Pricing, Excess Volatility, Variance Bounds, Risk Aversion, Imperfect Information.

JEL Classification: E44, G12.

${ }^{*}$ Forthcoming, European Economic Review. An earlier version of this paper was titled "Risk Aversion and Stock Price Volatility." We thank an anonymous referee for helpful comments and suggestions that significantly improved the paper. Part of this research was conducted while Lansing was a visiting economist at the Norges Bank, whose hospitality is gratefully acknowledged.

$\dagger$ Corresponding author. Research Department, Federal Reserve Bank of San Francisco, P.O. Box 7702, San Francisco, CA 94120-7702, (415) 974-2393, FAX: (415) 977-4031, email: kevin.j.lansing@sf.frb.org, homepage: www.frbsf.org/economics/economists/klansing.html

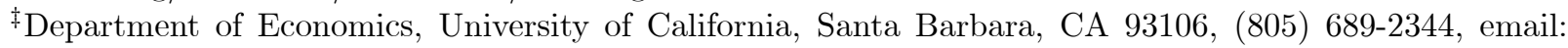
sleroy@econ.ucsb.edu, homepage: http://www.econ.ucsb.edu/ sleroy/webpage/ 


\section{Introduction}

Numerous empirical studies starting with Shiller (1981) and LeRoy and Porter (1981) concluded that U.S. stock market volatility appeared excessive when compared to the presentvalue of ex post realized dividends discounted at a constant rate, implying risk-neutral investors. A number of econometric problems with the empirical studies were later raised (e.g., Kleidon 1986, Marsh and Merton 1986), but it turned out that correcting these problems did not eliminate the appearance of excess volatility. ${ }^{1}$

Other studies around this time (e.g., Grossman and Shiller 1981, LeRoy and LaCivita 1981) recognized that allowing for risk aversion when discounting the stream of ex post realized dividends could increase volatility relative to the risk-neutral case. However, the hypothetical stock price series computed in this way was still only linked to a single information assumption, i.e., perfect foresight on the part of investors about the path of future dividends.

In this paper, we employ a standard Lucas-type asset pricing model with power utility and exponentially-growing dividends to derive theoretical volatility measures in a setting that allows for varying degrees of investor information about the dividend process. We examine four different information sets labeled $G_{t}, H_{t}, J_{t}$, and $I_{t}^{*}$ that contain progressively increasing amounts of information, i.e., $G_{t} \subseteq H_{t} \subseteq J_{t} \subseteq I_{t}^{*}$. Under set $G_{t}$, the investor can observe current and past dividend realizations but observations of trend dividend growth are contaminated with noise. This imperfect information setup is similar to one considered by Veronesi (2000). ${ }^{2}$ Set $H_{t}$ provides more information than set $G_{t}$ by allowing investors to directly observe trend growth and thereby identify the noise shocks. Set $J_{t}$ goes a step further by allowing investors to have one-period foresight about dividends and the trend growth rate. This setup captures the possibility that investors may have some auxiliary information that allows them to accurately forecast dividends and trend growth over the near-term. Information set $J_{t}$ connects to recent research on business cycles that focuses on "news shocks" as an important quantitative source of economic fluctuations. In these models, news shocks provide agents with auxiliary information about future technology innovations. ${ }^{3}$ Finally, set $I_{t}^{*}$ provides the maximum amount of investor information, corresponding to perfect knowledge about the entire stream of past and future dividends and trend growth rates. While this information assumption is obviously extreme, it provides a useful benchmark and helps connect our results to the earlier literature on stock market volatility mentioned above.

We demonstrate that the assumed degree of investor information can have significant

\footnotetext{
${ }^{1}$ For summaries of this extensive literature, see West (1988a), Gilles and LeRoy (1991), Shiller (2003), and LeRoy (2010).

${ }^{2}$ We employ a standard unobserved-component time series model for dividend growth. Veronesi (2000) considers a Markov switching process where investors receive a noisy signal about the drift parameter for dividends which can take on different values.

${ }^{3}$ See, for example, Barsky and Sims (2011).
} 
qualitative and quantitative impacts on the volatility of equity market variables in the model. The volatility of the price-dividend ratio increases monotonically with investor information but the relationship between investor information and equity return volatility can be nonmonotonic, depending on risk aversion and other parameter values. Put differently, providing investors with more information about the dividend process can either increase or decrease the volatility of the equity return. There also can be a non-monotonic relationship between investor information and the volatility of the excess return on equity, i.e., the equity premium.

The intuition for the complex relationship between investor information and return volatility is linked to the discounting mechanism. Two crucial elements are the persistence of trend dividend growth and the investor's discount factor (which depends on the coefficient or relative risk aversion). Both elements affect the degree to which future dividend innovations influence the perfect foresight price via discounting from the future to the present. When dividends are sufficiently persistent and the investor's discount factor is sufficiently close to unity, the discounting weights applied to successive future dividend innovations decay gradually. Since log returns are nearly the same as log price-changes, computation of the log return under information set $I_{t}^{*}$ tends to "difference out" the future dividend innovations, thus shrinking the magnitude of the perfect foresight return variance relative to the other information sets. In contrast, when dividend growth is less persistent and/or the investor's discount factor is much less than unity, the discounting weights applied to successive future dividend innovations decay rapidly. Consequently, these terms do not tend to difference out which serves to magnify the perfect foresight return variance relative to the other information sets. Similar logic applies when comparing return volatility under information set $J_{t}$ (one-period foresight) to return volatility under information sets $G_{t}$ or $H_{t}$.

The log return variance in our model is the analog to the arithmetic price-change variance examined by West (1988b) and Engel (2005) in risk-neutral settings with arithmeticallygrowing dividends. They show that the arithmetic price-change variance is a monotonically decreasing function of investors' information about future dividends. In contrast, we show that when investors are risk averse, the analogs to the West-Engel results do not go through; log return variance (or log price-change variance) is not a monotonic decreasing function of investors' information about future dividends. ${ }^{4}$ Our results have implications for the behavior of other asset prices, such as exchange rates. For example, Engel (2013, p. 11) states "...the variance of changes in the asset price falls with more information...[N]ews can account for a high variance in the real exchange rate, but not for a high variance in the change in the real exchange rate." Our results demonstrate that the variance of log returns (or log pricechanges) can rise with more information, thereby allowing new shocks to help account for the high variance of exchange rate changes or other asset price changes.

\footnotetext{
${ }^{4}$ On page 41, West (1988b) acknowledges that his result "may not extend immediately if logarithms or logarithmic differences are required to induce stationarity [of the dividend process]."
} 
As part of our quantitative analysis, we compare model-predicted volatilities to the corresponding values in long-run U.S. stock market data. Using plausible calibrations for the noisy dividend process and the coefficient of relative risk aversion, we show that some specifications of the model can match the standard deviations of the log price dividend ratio, the log equity return, and the log excess return on equity in the data. For the baseline calibration, modelpredicted volatility for the log price-dividend ratio can match the data only when investors are endowed with at least some knowledge about future dividends, i.e., information sets $J_{t}$ or $I_{t}^{*}$. The perfect foresight case requires a coefficient of relative risk aversion around 4 to match the data volatility. However, in Section 5 of the paper, we show that the model under information set $G_{t}$ (least information) can match the data volatility with a risk aversion coefficient around 5 if we allow for a highly-persistent trend growth process combined a more volatile noise shock (while still matching the moments of U.S. consumption growth). Overall, our results shows that in the absence of concrete knowledge about investors' information (e.g., whether investors have some news about future dividends or how much noise contaminates the dividend process), it becomes more difficult to conclude that the observed volatility in the data is excessive.

The remainder of the paper is organized as follows. Section 2 describes the model and the information setup. Section 3 examines how investor information influences the volatility of the price-dividend ratio. Section 4 extends the analysis to consider return volatility. Section 5 examines how the amount of noise in the dividend process affects volatility when trend dividend growth is unobservable. Section 6 concludes. An appendix provides the details for all derivations.

\section{Model}

We examine the effect of investor information in a standard Lucas (1978)-type asset pricing model with risk averse investors and exponentially-growing dividends. The representative investor can purchase equity shares to transfer wealth from one period to another. Each share pays an exogenous stream of stochastic dividends in perpetuity. The investor's problem is to maximize

$$
E_{0}\left\{\sum_{t=0}^{\infty} \beta^{t} \frac{c_{t}^{1-\alpha}-1}{1-\alpha} \mid I_{0}\right\},
$$

subject to the budget constraint

$$
c_{t}+p_{t} s_{t}=\left(p_{t}+d_{t}\right) s_{t-1}, \quad c_{t}, s_{t}>0
$$

where $c_{t}$ is the investor's consumption in period $t, \alpha$ is the coefficient of relative risk aversion and $s_{t}$ is the number of shares held in period $t$. We use the notation $E_{t}\left(\cdot \mid I_{t}\right)$ to represent 
the mathematical expectation operator, conditional on the investor's information set $I_{t}$, to be described more completely below.

The first-order condition that governs the investor's share holdings is

$$
p_{t}=E_{t}\left\{\beta\left(\frac{c_{t+1}}{c_{t}}\right)^{-\alpha}\left(p_{t+1}+d_{t+1}\right) \mid I_{t}\right\} .
$$

The first-order condition can be iterated forward to substitute out $p_{t+j}$ for $j=1,2, \ldots$ Applying the law of iterated expectations and imposing a transversality condition that excludes bubble solutions yields the following expression for the equilibrium equity price:

$$
p_{t}=E_{t}\left\{\sum_{j=1}^{\infty} M_{t, t+j} d_{t+j} \mid I_{t}\right\},
$$

where $M_{t, t+j} \equiv \beta^{j}\left(c_{t+j} / c_{t}\right)^{-\alpha}$ is the stochastic discount factor.

Equity shares are assumed to exist in unit net supply. Market clearing therefore implies $c_{t}=d_{t}$ for all $t$ such that the equity share represents a claim to consumption.

\subsection{Dividends and Investor Information}

The growth rate of dividends $x_{t} \equiv \log \left(d_{t} / d_{t-1}\right)=\log \left(c_{t} / c_{t-1}\right)$ is governed by a standard unobserved-component time series model:

$$
\begin{aligned}
x_{t} & =\tau_{x, t}+v_{t} \quad v_{t} \sim \operatorname{NID}\left(0, \sigma_{v}^{2}\right), \\
\tau_{x, t} & =\rho \tau_{x, t-1}+(1-\rho) \mu+\varepsilon_{t}, \quad|\rho|<1, \quad \varepsilon_{t} \sim N I D\left(0, \sigma_{\varepsilon}^{2}\right),
\end{aligned}
$$

where $\tau_{x, t}$ is the unobserved trend component of dividend growth and $v_{t}$ is a noise shock that is normally and independently distributed $(N I D)$ with mean zero and variance $\sigma_{v}^{2}$. The trend component evolves as an $\mathrm{AR}(1)$ process with mean $\mu$, persistence parameter $\rho$, and innovation variance $\sigma_{\varepsilon}^{2}$. The values of $\mu, \rho, \sigma_{v}^{2}$, and $\sigma_{\varepsilon}^{2}$ are assumed known to the investor. ${ }^{5}$ The precision of investor information about trend growth can be summarized by the signal-to-noise ratio $\sigma_{\varepsilon} / \sigma_{v}{ }^{6}$ When $\sigma_{\varepsilon} / \sigma_{v} \rightarrow \infty$, the noise shock becomes insignificant and we can write $x_{t}=\tau_{x, t}$. When $\sigma_{\varepsilon} / \sigma_{v} \rightarrow 0$, the trend component becomes insignificant and $x_{t}$ is NID.

\footnotetext{
${ }^{5}$ Given a long time series of observations of $x_{t}$, the investor can infer the values of $\mu, \rho, \sigma_{v}^{2}$, and $\sigma_{\varepsilon}^{2}$ from the unconditional moments of the time series.

${ }^{6}$ Here we will refer to $\sigma_{\varepsilon} / \sigma_{v}$ as the signal-to-noise ratio. The same term is also often applied to the ratio of the two variances, i.e., $\sigma_{\varepsilon}^{2} / \sigma_{v}^{2}$.
} 
We define the following refinements of the generalized investor information set $I_{t}$, where each set contains progressively increasing amounts of information about the dividend process:

$$
\begin{aligned}
& G_{t} \equiv\left\{d_{t}, d_{t-1}, d_{t-2}, \ldots\right\} \\
& H_{t} \equiv\left\{d_{t}, \tau_{x, t}, d_{t-1}, \tau_{x, t-1}, d_{t-2}, \tau_{x, t-2}, \ldots\right\} \\
& J_{t} \equiv\left\{d_{t+1}, \tau_{x, t+1}, d_{t}, \tau_{x, t}, d_{t-1}, \tau_{x, t-1}, d_{t-2}, \tau_{x, t-2}, \ldots\right\} \\
& I_{t}^{*} \equiv\left\{\ldots d_{t+2}, \tau_{x, t+2}, d_{t+1}, \tau_{x, t+1}, d_{t}, \tau_{x, t}, d_{t-1}, \tau_{x, t-1}, d_{t-2}, \tau_{x, t-2}, \ldots\right\}
\end{aligned}
$$

such that $G_{t} \subseteq H_{t} \subseteq J_{t} \subseteq I_{t}^{*}$. Set $G_{t}$ contains the least amount of investor information among the four sets; the investor can observe current and past dividend realizations but trend dividend growth cannot be observed directly due to the presence of noise. Set $I_{t}^{*}$ provides the maximum amount of investor information, corresponding to perfect knowledge about the entire stream of past and future dividends and trend growth rates. In between these two, set $H_{t}$ provides more information than set $G_{t}$ by allowing investors to directly observe current and past trend growth rates. These observations allow the investor to identify the noise shocks in equation (5). Set $J_{t}=H_{t} \cup\left\{d_{t+1}, \tau_{x, t+1}\right\}$ goes a step further by allowing investors to have one-period foresight regarding dividends and trend growth at time $t+1$. Along the lines of LeRoy and Parke (1992), set $J_{t}$ entertains the possibility that investors receive some news that allows them to forecast these variables over the near-term without error.

Throughout the paper, we adopt the notation of using unmarked variables (such as $p_{t}$ ) to denote variables computed using the generalized information set $I_{t}$ and superscripts " $G$," " $H$," " $J$," or "*" to denote variables computed using information sets $G_{t}, H_{t}, J_{t}$, or $I_{t}^{*}$, respectively.

Starting from equation (4), the perfect foresight (or ex post rational) equity price is given by

$$
p_{t}^{*}=\sum_{j=1}^{\infty} M_{t, t+j} d_{t+j},
$$

which implies the following relationship $p_{t}=E_{t}\left(p_{t}^{*} \mid I_{t}\right)$.

\section{Volatility of the Price-Dividend Ratio}

In a setting with exponentially-growing dividends, the equilibrium stock price will trend upward, such that variance measures conditional on some initial date will increase with time. Here we correct for trend by working with the price-dividend ratio and the rate of return 
which are stationary variables in the model. ${ }^{7}$

The price-dividend ratios implied by the various information sets are defined by $y_{t}^{G} \equiv$ $p_{t}^{G} / d_{t}, y_{t}^{H} \equiv p_{t}^{H} / d_{t}, y_{t}^{J} \equiv p_{t}^{J} / d_{t}$, and $y_{t}^{*} \equiv p_{t}^{*} / d_{t}$. By substituting the equilibrium condition $c_{t}=d_{t}$ into the first-order condition (3), the first-order conditions for the various information sets can be written as

$$
\begin{aligned}
y_{t}^{G} & =E_{t}\left\{\beta \exp \left[(1-\alpha) x_{t+1}\right]\left(y_{t+1}^{G}+1\right) \mid G_{t}\right\}, \\
y_{t}^{H} & =E_{t}\left\{\beta \exp \left[(1-\alpha) x_{t+1}\right]\left(y_{t+1}^{H}+1\right) \mid H_{t}\right\}, \\
y_{t}^{J} & =E_{t}\left[\beta \exp \left[(1-\alpha) x_{t+1}\right]\left(y_{t+1}^{J}+1\right) \mid J_{t}\right], \\
y_{t}^{*} & =\beta \exp \left[(1-\alpha) x_{t+1}\right]\left(y_{t+1}^{*}+1\right),
\end{aligned}
$$

where we have dropped the expectation operator for information set $I_{t}^{*}$.

For the generalized information set $I_{t}$, we have $p_{t}=E_{t}\left(p_{t}^{*} \mid I_{t}\right)$. The price-dividend ratios $y_{t}^{G}$, $y_{t}^{H}, y_{t}^{J}$, and $y_{t}^{*}$ all have the same denominator $d_{t}$ which is known at time $t$ under all information sets. Given that sets (7) through (10) contain progressively increasing amounts of information about dividends, we can write $y_{t}^{G}=E_{t}\left(y_{t+1}^{*} \mid G_{t}\right), y_{t}^{H}=E_{t}\left(y_{t+1}^{*} \mid H_{t}\right)$, and $y_{t}^{J}=E_{t}\left(y_{t+1}^{*} \mid J_{t}\right)$. We therefore have

$$
\operatorname{Var}\left(y_{t}^{G}\right) \leq \operatorname{Var}\left(y_{t}^{H}\right) \leq \operatorname{Var}\left(y_{t}^{J}\right) \leq \operatorname{Var}\left(y_{t}^{*}\right)
$$

which recovers the basic form of the variance bound originally derived by LeRoy and Porter (1981), but now extended to allow for risk aversion and exponentially-growing dividends. We now proceed to solve for the equilibrium price-dividend ratio under each information set.

\subsection{Unobserved Trend: Information Set $G_{t}$}

Our solution for the equilibrium price-dividend ratio employs an analytical perturbation method. ${ }^{8}$ We solve the first-order condition (12) subject to the dividend growth process (5) and (6). There are two state variables: observed dividend growth $x_{t} \equiv \log \left(d_{t} / d_{t-1}\right)$ and

\footnotetext{
${ }^{7}$ The early literature on stock market volatility often assumed that dividends and stock prices were stationary, either in levels or logarithms. West (1988a, p. 641) summarizes the various assumptions made in the earlier literature.

${ }^{8}$ Lansing (2010) demonstrates the accuracy of this solution method for the level of the price-dividend ratio in the noiseless case $\left(\sigma_{v}=0\right)$. Here we focus on the variance of the price-dividend ratio and variance of the equity return. Variance measures are not affected by constant terms in the perturbation solutions, which can be an important source of approximation error when the point of approximation is the deterministic steady state (Collard and Juillard 2001). As in Lansing (2010), the point of approximation for our solution method is the ergodic mean, not the deterministic steady state, which helps to improve accuracy.
} 
the lagged Kalman filter estimate of trend growth $\bar{x}_{t-1} \equiv E_{t-1}\left(\tau_{x, t} \mid G_{t-1}\right)$. The investor's estimate of trend growth evolves according to the following Kalman filter updating equation:

$$
\begin{aligned}
& \underbrace{E_{t}\left(\tau_{x, t+1} \mid G_{t}\right)}_{\equiv \bar{x}_{t}}=\rho\left[\lambda x_{t}+(1-\lambda) \bar{x}_{t-1}\right]+(1-\rho) \mu, \\
& \lambda=\frac{\left(\sigma_{\varepsilon} / \sigma_{v}\right)^{2}-\left(1-\rho^{2}\right)+\sqrt{\left(\sigma_{\varepsilon} / \sigma_{v}\right)^{4}+2\left(\sigma_{\varepsilon} / \sigma_{v}\right)^{2}\left(1+\rho^{2}\right)+\left(1-\rho^{2}\right)^{2}}}{2+\left(\sigma_{\varepsilon} / \sigma_{v}\right)^{2}-\left(1-\rho^{2}\right)+\sqrt{\left(\sigma_{\varepsilon} / \sigma_{v}\right)^{4}+2\left(\sigma_{\varepsilon} / \sigma_{v}\right)^{2}\left(1+\rho^{2}\right)+\left(1-\rho^{2}\right)^{2}}},
\end{aligned}
$$

where $\lambda \in[0,1]$ is the converged Kalman gain parameter. ${ }^{9}$ As $\sigma_{\varepsilon} / \sigma_{v} \rightarrow 0$, we have $\lambda=0$ such that $\bar{x}_{t}$ is simply the unconditional mean of past dividend growth rates, as given by $\mu$. As $\sigma_{\varepsilon} / \sigma_{v} \rightarrow \infty$, we have $\lambda=1$, such that $\bar{x}_{t}=\rho x_{t}+(1-\rho) \mu$.

We make the standard assumption that the investor's first-order condition (12) is not altered by the existence of the filtering problem. ${ }^{10}$ To solve for the equilibrium price-dividend ratio, it is convenient to define the following nonlinear change of variables:

$$
z_{t}^{G} \equiv \beta \exp \left[(1-\alpha) x_{t}\right]\left(y_{t}^{G}+1\right)
$$

where $z_{t}^{G}$ represents a composite variable that depends on both the growth rate of dividends $x_{t}$ and the price-dividend ratio $y_{t}^{G}$. The first-order condition (12) becomes

$$
y_{t}^{G}=E_{t}\left(z_{t+1}^{G} \mid G_{t}\right)
$$

implying that $y_{t}^{G}$ is simply the investor's forecast of the composite variable $z_{t+1}^{G}$, conditioned on information set $G_{t}$. Combining (19) and (20), the composite variable $z_{t}^{G}$ is seen to be governed by the following equilibrium condition:

$$
z_{t}^{G}=\beta \exp \left[(1-\alpha) x_{t}\right]\left[E_{t}\left(z_{t+1}^{G} \mid G_{t}\right)+1\right]
$$

which shows that the value of $z_{t}^{G}$ in period $t$ depends on the investor's conditional forecast of that same variable. The following proposition presents an approximate analytical solution for the composite variable $z_{t}^{G}$.

Proposition 1. An approximate analytical solution for the equilibrium value of the composite variable $z_{t}^{G}$ under information set $G_{t}$ is given by

$$
z_{t}^{G}=g_{0} \exp \left[g_{1}\left(x_{t}-\mu\right)+g_{2}\left(\bar{x}_{t-1}-\mu\right)\right]
$$

\footnotetext{
${ }^{9}$ For details regarding the Kalman filter, see Harvey (1993). The solution to the filtering problem employed here follows Gourinchas and Tornell (2004) and Gilchrist and Saito (2008).

${ }^{10}$ See, for example, Cogley and Sargent (2008).
} 
where $g_{0}, g_{1}$, and $g_{2}$ solve

$$
\begin{aligned}
& g_{0}=\frac{\beta \exp [(1-\alpha) \mu]}{1-\beta \exp \left[(1-\alpha) \mu+\frac{1}{2}\left(g_{1}\right)^{2}\left(\sigma_{\varepsilon}^{2}+\sigma_{v}^{2}\right)\right]}, \\
& g_{1}=\frac{(1-\alpha)\left\{1-(1-\lambda) \rho \beta \exp \left[(1-\alpha) \mu+\frac{1}{2}\left(g_{1}\right)^{2}\left(\sigma_{\varepsilon}^{2}+\sigma_{v}^{2}\right)\right]\right\}}{1-\rho \beta \exp \left[(1-\alpha) \mu+\frac{1}{2}\left(g_{1}\right)^{2}\left(\sigma_{\varepsilon}^{2}+\sigma_{v}^{2}\right)\right]}, \\
& g_{2}=\frac{(1-\alpha)(1-\lambda) \rho \beta \exp \left[(1-\alpha) \mu+\frac{1}{2}\left(g_{1}\right)^{2}\left(\sigma_{\varepsilon}^{2}+\sigma_{v}^{2}\right)\right]}{1-\rho \beta \exp \left[(1-\alpha) \mu+\frac{1}{2}\left(g_{1}\right)^{2}\left(\sigma_{\varepsilon}^{2}+\sigma_{v}^{2}\right)\right]}
\end{aligned}
$$

with $\lambda$ given by equation (18), provided that $\beta \exp \left[(1-\alpha) \mu+\frac{1}{2}\left(g_{1}\right)^{2}\left(\sigma_{\varepsilon}^{2}+\sigma_{v}^{2}\right)\right]<1$.

Proof: See Appendix A.1.

Two values of $g_{1}$ satisfy the nonlinear equation in Proposition 1 . The inequality restriction selects the value of $g_{1}$ with lower magnitude to ensure that $g_{0}=\exp \left\{E\left[\log \left(z_{t}^{G}\right)\right]\right\}$ is positive. Given the solution for the composite variable $z_{t}^{G}$, we can recover the price-dividend ratio $y_{t}^{G}$ as follows:

$$
\begin{aligned}
y_{t}^{G}=E_{t}\left(z_{t+1}^{G} \mid G_{t}\right) & =E_{t}\left\{g_{0} \exp \left[g_{1}\left(x_{t+1}-\mu\right)+g_{2}\left(\bar{x}_{t}-\mu\right)\right] \mid G_{t}\right\} \\
& =g_{0} \exp \left[\left(g_{1}+g_{2}\right)\left(\bar{x}_{t}-\mu\right)+\frac{1}{2}\left(g_{1}\right)^{2}\left(\sigma_{\varepsilon}^{2}+\sigma_{v}^{2}\right)\right],
\end{aligned}
$$

where we have used $E_{t}\left(x_{t+1} \mid G_{t}\right)=E_{t}\left(\tau_{x, t+1} \mid G_{t}\right) \equiv \bar{x}_{t}$. The above solution yields the following unconditional variance of the log price-dividend ratio:

$$
\operatorname{Var}\left[\log \left(y_{t}^{G}\right)\right]=\left(g_{1}+g_{2}\right)^{2} \operatorname{Var}\left(\bar{x}_{t}\right)
$$

where the expression for $\operatorname{Var}\left(\bar{x}_{t}\right)$ is shown in Appendix A.2. Given $\operatorname{Var}\left[\log \left(y_{t}^{G}\right)\right]$, it is straightforward to derive an expression for $\operatorname{Var}\left(y_{t}^{G}\right){ }^{11}$

From equation (23), we can see how different levels of risk aversion affect the variance of $\log \left(y_{t}^{G}\right)$. In the special case of logarithmic utility, we have $\alpha=1$ such that $g_{1}=g_{2}=0$. In this case, fluctuations in dividend growth do not affect $\log \left(y_{t}^{G}\right)$, which is therefore constant. This is because the income and substitution effects of a shock to dividend growth are exactly offsetting with $\log$ utility. When $\alpha<1$, an increase in $\alpha$ shrinks the magnitude of $g_{1}$ and $g_{2}$ which moves the variance of $\log \left(y_{t}^{G}\right)$ toward zero. This happens because fluctuations in

\footnotetext{
${ }^{11}$ Given the unconditional mean $E\left[\log \left(y_{t}^{G}\right)\right]=\log \left(g_{0}\right)+\left(g_{1}\right)^{2}\left(\sigma_{\varepsilon}^{2}+\sigma_{v}^{2}\right) / 2$ and the expression for $\operatorname{Var}\left[\log \left(y_{t}^{G}\right)\right]$ from equation (23), the unconditional variance of $y_{t}^{G}$ can be computed by making use of the following relationships for the mean and variance of the log-normal distribution: $E\left(y_{t}^{G}\right)=$ $\exp \left\{E\left[\log \left(y_{t}^{G}\right)\right]+\frac{1}{2} \operatorname{Var}\left[\log \left(y_{t}^{G}\right)\right]\right\}$ and $\operatorname{Var}\left(y_{t}^{G}\right)=E\left(y_{t}^{G}\right)^{2}\left\{\exp \left(\operatorname{Var}\left[\log \left(y_{t}^{G}\right)\right]\right)-1\right\}$.
} 
dividend growth are increasingly offset by fluctuations in their marginal utility; the closer $\alpha$ is to unity, the greater is the offset. When $\alpha>1$, an increase in $\alpha$ raises the magnitude of $g_{1}$ and $g_{2}$, thereby increasing the variance of $\log \left(y_{t}^{G}\right)$. Consequently, the variance of $\log \left(y_{t}^{G}\right)$ is a $\mathrm{V}$-shaped function of $\alpha$, centered at $\alpha=1$.

\subsection{Observed Trend: Information Set $H_{t}$}

Under set $H_{t}$, investors can separately observe trend growth $\tau_{x, t}$ and the noise shock $v_{t}$ which now become the two state variables. The following proposition presents an approximate analytical solution for the composite variable $z_{t}^{H} \equiv \beta \exp \left[(1-\alpha) x_{t}\right]\left(y_{t}^{H}+1\right)$.

Proposition 2. An approximate analytical solution for the equilibrium value of the composite variable $z_{t}^{H}$ under information set $H_{t}$ is given by

$$
z_{t}^{H}=h_{0} \exp \left[h_{1}\left(\tau_{x, t}-\mu\right)+h_{2} v_{t}\right]
$$

where $h_{0}, h_{1}$, and $h_{2}$ solve

$$
\begin{aligned}
& h_{0}=\frac{\beta \exp [(1-\alpha) \mu]}{1-\beta \exp \left[(1-\alpha) \mu+\frac{1}{2}\left(h_{1}\right)^{2} \sigma_{\varepsilon}^{2}+\frac{1}{2}\left(h_{2}\right) \sigma_{v}^{2}\right]}, \\
& h_{1}=\frac{1-\alpha}{1-\rho \beta \exp \left[(1-\alpha) \mu+\frac{1}{2}\left(h_{1}\right)^{2} \sigma_{\varepsilon}^{2}+\frac{1}{2}\left(h_{2}\right) \sigma_{v}^{2}\right]}, \\
& h_{2}=1-\alpha,
\end{aligned}
$$

provided that $\beta \exp \left[(1-\alpha) \mu+\frac{1}{2}\left(h_{1}\right)^{2} \sigma_{\varepsilon}^{2}+\frac{1}{2}\left(h_{2}\right) \sigma_{v}^{2}\right]<1$.

Proof: See Appendix B.1.

Given the above solution, we can recover $y_{t}^{H}$ and compute $\operatorname{Var}\left[\log \left(y_{t}^{H}\right)\right]$. The results are:

$$
\begin{aligned}
& y_{t}^{H}=E_{t}\left(z_{t+1}^{H} \mid H_{t}\right)=h_{0} \exp \left[h_{1} \rho\left(\tau_{x, t}-\mu\right)+\frac{1}{2}\left(h_{1}\right)^{2} \sigma_{\varepsilon}^{2}+\frac{1}{2}\left(h_{2}\right)^{2} \sigma_{v}^{2}\right], \\
& \operatorname{Var}\left[\log \left(y_{t}^{H}\right)\right]=\left(h_{1} \rho\right)^{2} \operatorname{Var}\left(\tau_{x, t}\right),
\end{aligned}
$$

where $\operatorname{Var}\left(\tau_{x, t}\right)=\sigma_{\varepsilon}^{2} /\left(1-\rho^{2}\right)$ from equation (5). Notice that the variance of the noise shock $\sigma_{v}^{2}$ can influence the variance of $\log \left(y_{t}^{H}\right)$ only via the solution coefficient $h_{1}$. When either $\alpha=1$ ( $\log$ utility) or $\rho=0$ (trend growth is $N I D$ ), we have $h_{1}=0$ and the price-dividend ratio $y_{t}^{H}$ is constant. Similarly, Proposition 1 shows that $\alpha=1$ yields $g_{1}=g_{2}=0$ while $\rho=0$ yields $g_{1}+g_{2}=0$. Hence, $y_{t}^{G}$ is also constant in these two special cases. 


\subsection{One-Period Foresight: Information Set $J_{t}$}

In the preceding subsection we assumed that investors have no auxiliary information or news that would help to predict future dividends. An example of such auxiliary information might be company-provided guidance about future financial performance that is typically disseminated to investors via quarterly conference calls. To capture this idea, we consider an environment where investors can see dividends and trend growth one period ahead without error, as in LeRoy and Parke (1992).

As shown in Appendix C.1, the expanded information set $J_{t}$ implies the following relationships:

$$
\begin{aligned}
p_{t}^{J} & =M_{t, t+1}\left(d_{t+1}+p_{t+1}^{H}\right), \\
y_{t}^{J} & =\beta \exp \left[(1-\alpha) x_{t+1}\right]\left(y_{t+1}^{H}+1\right), \\
& =z_{t+1}^{H}=h_{0} \exp \left[h_{1}\left(\tau_{x, t+1}-\mu\right)+h_{2} v_{t+1}\right],
\end{aligned}
$$

where $p_{t}^{J}$ and $y_{t}^{J}$ are the price and price-dividend ratio under information set $J_{t}$. The assumption of one-period foresight implies that $M_{t, t+1}, d_{t+1}$, and $x_{t+1}$ are all known to investors at time $t$. However, going forward from time $t+1$, the investor will be faced with information set $H_{t+1}$ where $M_{t+1, t+2}, d_{t+2}$, and $x_{t+2}$ are not known. Hence, $p_{t+1}^{H}$ and $y_{t+1}^{H}$ are the equilibrium variables that prevail at time $t+1$. In equation (27), we have employed the definition of $z_{t+1}^{H}$ and the solution in Proposition 2. From equations (24) and (27), it follows directly that $y_{t}^{H}=E_{t}\left(y_{t}^{J} \mid H_{t}\right)$, which in turn implies $\operatorname{Var}\left(y_{t}^{H}\right) \leq \operatorname{Var}\left(y_{t}^{J}\right)$.

Equation (27) implies the following unconditional variance:

$$
\operatorname{Var}\left[\log \left(y_{t}^{J}\right)\right]=\left(h_{1}\right)^{2} \operatorname{Var}\left(\tau_{x, t}\right)+\left(h_{2}\right)^{2} \sigma_{v}^{2}
$$

Comparing the above expression to $\operatorname{Var}\left[\log \left(y_{t}^{H}\right)\right]$ from equation (25) confirms the ordering $\operatorname{Var}\left[\log \left(y_{t}^{H}\right)\right] \leq \operatorname{Var}\left[\log \left(y_{t}^{J}\right)\right]$ since $|\rho|<1$. Unlike the preceding information sets, the value of $y_{t}^{J}$ is not constant when $\rho=0$ but instead continues to move in response to the anticipated values of trend growth $\tau_{x, t+1}$ and the noise shock $v_{t+1}$.

\subsection{Perfect Foresight: Information Set $I_{t}^{*}$}

The assumption of perfect foresight represents an upper bound on the investor's information about the dividend process. While this information assumption is obviously extreme, it provides a useful benchmark for the analysis of stock market volatility, going back to the original contributions of Shiller (1981) and LeRoy and Porter (1981). 
The perfect foresight price-dividend ratio $y_{t}^{*}$ is governed by equation (15), which is a nonlinear law of motion. As shown in Appendix D.1, we can approximate equation (15) using the following log-linear law of motion:

$$
\log \left(y_{t}^{*}\right)-E\left[\log \left(y_{t}^{*}\right)\right]=(1-\alpha)\left(x_{t+1}-\mu\right)+\beta \exp [(1-\alpha) \mu]\left\{\log \left(y_{t+1}^{*}\right)-E\left[\log \left(y_{t}^{*}\right)\right]\right\}
$$

We use the log-linear law of motion (29) to derive the following unconditional variance (Appendix D.2):

$$
\operatorname{Var}\left[\log \left(y_{t}^{*}\right)\right]=\frac{(1-\alpha)^{2}}{\left\{1-\beta^{2} \exp [2(1-\alpha) \mu]\right\}}\left\{\frac{1+\rho \beta \exp [(1-\alpha) \mu]}{1-\rho \beta \exp [(1-\alpha) \mu]} \operatorname{Var}\left(\tau_{x, t}\right)+\sigma_{v}^{2}\right\},
$$

which is considerably more complicated than either $\operatorname{Var}\left[\log \left(y_{t}^{H}\right)\right]$ from equation (23) or $\operatorname{Var}\left[\log \left(y_{t}^{J}\right)\right]$ from equation (28). Similar to the case of set $J_{t}$, the above expression implies $\operatorname{Var}\left[\log \left(y_{t}^{*}\right)\right]=0$ when $\alpha=1$ but $\operatorname{Var}\left[\log \left(y_{t}^{*}\right)\right]>0$ when $\rho=0$. When $\rho=0$, we have the following result: $\left.0=\operatorname{Var}\left[\log \left(y_{t}^{G}\right)\right]=\operatorname{Var}\left[\log \left(y_{t}^{H}\right)\right] \leq \operatorname{Var}\left[\log \left(y_{t}^{J}\right)\right] \leq \operatorname{Var}\left[\log y_{t}^{*}\right)\right]$.

\subsection{Model Calibration}

We now turn to a quantitative analysis of the model's predictions for the volatility of the log price-dividend ratio. There are six parameter values to be chosen: four pertain to the dividend process $\left(\mu, \rho, \sigma_{\varepsilon}\right.$, and $\left.\sigma_{v}\right)$ and two pertain to the investor's preferences $(\alpha$ and $\beta)$.

Given that an equity share in our model represents a consumption claim, we calibrate the process for $x_{t}$ in equations (5) and (6) using U.S. data on real per capita aggregate consumption (services and nondurable goods) from 1930 to 2012. ${ }^{12}$ Given a target value for the signal-to-noise ratio $\sigma_{\varepsilon} / \sigma_{v}$, we choose values for $\mu, \rho, \sigma_{\varepsilon}$, and $\sigma_{v}$ to match the mean, autocorrelation, and standard deviation of U.S. consumption growth, as summarized in Table 1.13

Table 1: Calibrated Parameter Values

\begin{tabular}{cccc}
\hline \hline & Baseline & Higher Noise & \multicolumn{1}{c}{ Target } \\
Parameter & $\sigma_{\varepsilon} / \sigma_{v}=2$ & $\sigma_{\varepsilon} / \sigma_{v}=0.775$ & \multicolumn{1}{c}{ T $\left(x_{t}\right)=1.86 \%$} \\
$\rho$ & 0.0186 & 0.0186 & $\operatorname{Corr}\left(x_{t}, x_{t-1}\right)=0.50$ \\
$\sigma_{\varepsilon}$ & 0.583 & 0.800 & $\operatorname{Std} \operatorname{Dev}\left(x_{t}\right)=2.16 \%$ \\
$\sigma_{v}$ & 0.0162 & 0.0102 & $\sigma_{\varepsilon} / \sigma_{v}=2$ or 0.775 \\
\hline
\end{tabular}

Note: Target moments based on U.S. real per capita consumption growth, 1930 to 2012 .

\footnotetext{
${ }^{12}$ Data on nominal consumption expenditures for services and nondurable goods are from the Bureau of Economic Analysis, NIPA Table 2.3.5, lines 8 and 13. The corresponding price indices are from Table 2.3.4, lines 8 and 13. Population data are from Table 2.1, line 40.

${ }^{13}$ The moment formulas implied by equations equations (5) are (6) are shown in Appendix A.2
} 
We initially consider two values for the target signal-to-noise ratio: a baseline value of $\sigma_{\varepsilon} / \sigma_{v}=2$ and an alternative "higher noise" value of $\sigma_{\varepsilon} / \sigma_{v}=0.775$. The higher noise calibration requires a higher value for the trend growth persistence parameter $(\rho=0.8)$ in order to match the autocorrelation of U.S. consumption growth. From equation (18), the value of the Kalman gain parameter is $\lambda=0.810$ for the baseline calibration and $\lambda=0.819$ for the higher noise calibration. Later, in Section 5, we will examine the sensitivity of our results to a much wider range of values for the target signal-to-noise ratio.

Table 2 compares the moments in the data versus those in the model for the two values of $\sigma_{\varepsilon} / \sigma_{v}$. The baseline calibration with $\sigma_{\varepsilon} / \sigma_{v}=2$ does better at matching $\operatorname{Corr}\left(x_{t}, x_{t-2}\right)$ and $\operatorname{Corr}\left(\Delta x_{t}, \Delta x_{t-1}\right)$ in the data.

Table 2. Moments of Consumption Growth: Data versus Model

\begin{tabular}{lccc}
\hline \hline \multicolumn{1}{c}{ Statistic } & U.S. Data & Baseline & Higher Noise \\
& 1930 to 2012 & $\sigma_{\varepsilon} / \sigma_{v}=2$ & $\sigma_{\varepsilon} / \sigma_{v}=0.775$ \\
\hline Mean $\left(x_{t}\right)$ & 0.0186 & 0.0186 & 0.0186 \\
Std Dev $\left(x_{t}\right)$ & 0.0216 & 0.0216 & 0.0216 \\
Std Dev $\left(\Delta x_{t}\right)$ & 0.0211 & 0.0215 & 0.0215 \\
$\operatorname{Corr}\left(x_{t}, x_{t-1}\right)$ & 0.50 & 0.50 & 0.50 \\
$\operatorname{Corr}\left(x_{t}, x_{t-2}\right)$ & 0.19 & 0.29 & 0.40 \\
$\operatorname{Corr}\left(\Delta x_{t}, \Delta x_{t-1}\right)$ & -0.21 & -0.29 & -0.40 \\
\hline Note: Data source is Bureau of Economic Analysis, NIPA tables 2.1, 2.3.4, and 2.3.5.
\end{tabular}

Given the parameter values from Table 1 and the expression for the price-dividend ratio under set $G_{t}$, we choose the value of the subjective time discount factor $\beta$ to achieve $E\left[\log \left(y_{t}^{G}\right)\right]=3.21$, consistent with the sample mean of the log price-dividend ratio for the S\&P 500 stock index from 1871 to 2012. For example, when the coefficient of relative risk aversion is $\alpha=2$, this procedure yields $\beta=0.978$ for the baseline calibration and $\beta=0.977$ for the higher noise calibration. ${ }^{14}$ The same value of $\beta$ is used for all information sets. Whenever $\alpha$ or the parameters of the dividend process are changed, the value of $\beta$ is recalibrated to maintain $E\left[\log \left(y_{t}^{G}\right)\right]=3.21$. When $\alpha$ exceeds a value slightly above 3 , achieving the target value $E\left[\log \left(y_{t}^{G}\right)\right]=3.21$ requires a $\beta$ value greater than unity. Nevertheless, for all values of $\alpha$ examined, the mean value of the stochastic discount factor $E\left[\beta\left(c_{t+1} / c_{t}\right)^{-\alpha}\right]$ remains below unity. $^{15}$

\footnotetext{
${ }^{14}$ Cochrane (1992) employs a similar calibration procedure. For a given discount factor $\beta$, he chooses the risk aversion coefficient $\alpha$ to match the mean price-dividend ratio in the data.

${ }^{15}$ Kocherlakota (1990) shows that a well-defined competitive equilibrium with positive interest rates can still exist in growth economies when $\beta>1$.
} 


\subsection{Quantitative Analysis}

Figure 1 plots the model-implied standard deviations of the log price dividend ratio for each of the four information sets over the range $0 \leq \alpha \leq 10 .{ }^{16}$ Specifically, we plot the standard deviations of $\log \left(y_{t}^{G}\right)$ (dotted line), $\log \left(y_{t}^{H}\right)$ (dashed line), $\log \left(y_{t}^{J}\right)$ (dash-dotted line), and $\log \left(y_{t}^{*}\right)$ (solid line). The horizontal dashed line at the value 0.427 is the standard deviation of the log-price dividend ratio in U.S. data from 1871 to $2012 .{ }^{17}$ The top panel shows the results for the baseline calibration while the bottom panel shows the results for the higher noise calibration. Both calibrations match the moments of U.S. consumption growth, as shown in Table 2.

[Figure 1 about here]

Under all information sets, the model-implied standard deviation is a V-shaped function centered at $\alpha=1$, corresponding to $\log$ utility. For any $\alpha \neq 1$, the standard deviation of $\log \left(y_{t}^{G}\right)$ is the lowest while the standard deviation of $\log \left(y_{t}^{*}\right)$ is the highest. Moving vertically in the figure, volatility increases monotonically with investor information about the dividend process, consistent with the theoretical inequality (16). The volatility results for sets $G_{t}$ and $H_{t}$ are quantitatively similar under the baseline calibration, but exhibit more divergence under the higher noise calibration. Recall that the noise shock is directly observable for set $H_{t}$ but not $G_{t}$.

For the baseline calibration (top panel of Figure 1), model-predicted volatility can match the data volatility only when investors are endowed with at least some knowledge about future dividends, i.e., information sets $J_{t}$ or $I_{t}^{*}$. For example, under perfect foresight $I_{t}^{*}$ the model requires $\alpha \simeq 4.4$ to match the volatility of the log price-dividend ratio in the data. This result is reminiscent of Grossman and Shiller (1981) who employ an informal visual comparison to conclude that a risk aversion coefficient around 4 is needed to make the perfect foresight stock price computed from ex post realized dividends in the data look about as volatile as a plot of the S\&P 500 stock price index.

For the higher noise calibration (bottom panel of Figure 1), model-predicted volatility can match the data volatility with $\alpha \leq 10$ under all four information sets. However, in the case of sets $G_{t}$ and $H_{t}$, the required level of risk aversion is near the limit of the plausible range. For example, model-predicted volatility under set $G_{t}$ (least information) can match the data when $\alpha \simeq 9.5$. Recall that the higher noise calibration employs a higher value for the trend growth persistence parameter of $\rho=0.8$ in order to match the autocorrelation of U.S. consumption growth (Table 1). At the higher value of $\rho$, the trend growth process (6) is closer to a unit root specification which serves to magnify the volatility of the model price-dividend ratio. Later,

\footnotetext{
${ }^{16}$ Mehra and Prescott (1985) argue that risk aversion coefficients that fall within this range are plausible.

${ }^{17}$ The standard deviation of the price dividend ratio in levels (as opposed to logarithms) is 14.2, with a corresponding mean value of 27.3 .
} 
in Section 5, we will examine the relationship between noise and model-predicted volatility in more detail.

The early literature on tests for excess volatility in stock prices typically assumed that investors were risk neutral, i.e., $\alpha=0 .{ }^{18}$ At the far left of Figure 1, we see that both model calibrations substantially underpredict the data volatility when $\alpha=0$. In other words, restricting attention to a risk-neutral environment would lead one to conclude that observed volatility in the data is excessive relative to what can be explained by a reasonably-calibrated asset pricing model. However, if the analysis is expanded (as done here) to consider a richer model that allows for risk aversion and a variety of different investor information sets, then it becomes more difficult to conclude that the data volatility is excessive. This is particularly true if one allows for investor information about future dividends. A finding of excess volatility in the data relative to the model's theoretical prediction requires: (1) knowledge of the information set used by the investor to make conditional forecasts, (2) the value of the representative investor's risk aversion coefficient $\alpha$, and (3) the amount of noise present in the dividend process, as measured by the signal-to-noise ratio $\sigma_{\varepsilon} / \sigma_{v}$.

\section{Return Volatility}

\subsection{Equity Return}

We now examine the relationship between investor information and the volatility of the log equity return, i.e., $\log \left(R_{t+1}\right)$ where $R_{t+1}=\left(p_{t+1}+d_{t+1}\right) / p_{t}$ is the gross rate of return on equity. ${ }^{19}$ Rewriting the gross return in terms of stationary variables for each information set yields:

$$
\begin{aligned}
& R_{t+1}^{G}=\exp \left(x_{t+1}\right)\left(\frac{y_{t+1}^{G}+1}{y_{t}^{G}}\right)=\beta^{-1} \exp \left(\alpha x_{t+1}\right)\left[\frac{z_{t+1}^{G}}{E_{t}\left(z_{t+1}^{G} \mid G_{t}\right)}\right], \\
& R_{t+1}^{H}=\exp \left(x_{t+1}\right)\left(\frac{y_{t+1}^{H}+1}{y_{t}^{H}}\right)=\beta^{-1} \exp \left(\alpha x_{t+1}\right)\left[\frac{z_{t+1}^{H}}{E_{t}\left(z_{t+1}^{H} \mid H_{t}\right)}\right], \\
& R_{t+1}^{J}=\exp \left(x_{t+1}\right)\left(\frac{y_{t+1}^{J}+1}{y_{t}^{J}}\right)=\beta^{-1} \exp \left(\alpha x_{t+1}\right)\left[\frac{z_{t+1}^{J}}{E_{t}\left(z_{t+1}^{J} \mid J_{t}\right)}\right], \\
& R_{t+1}^{*}=\exp \left(x_{t+1}\right)\left(\frac{y_{t+1}^{*}+1}{y_{t}^{*}}\right)=\beta^{-1} \exp \left(\alpha x_{t+1}\right) .
\end{aligned}
$$

\footnotetext{
${ }^{18}$ For an overview of this literature, see LeRoy (2010).

${ }^{19}$ Very similar results are obtained for the volatility of the log price-change, i.e., $\log \left(p_{t+1} / p_{t}\right)$. Over the period 1871 to 2012, the correlation coefficient between log real price changes and log real equity returns in U.S. annual data is 0.996 . LeRoy $(1984$, p. 186) shows that the unconditional variance of price changes is numerically very close to the conditional variance of prices in a model with stationary dividends.
} 
In the expression for $R_{t+1}^{G}$, we have eliminated $y_{t}^{G}$ using the equilibrium condition (20) and eliminated $y_{t+1}^{G}+1$ using the definitional relationship

$$
y_{t+1}^{G}+1=z_{t+1}^{G} \beta^{-1} \exp \left[-(1-\alpha) x_{t+1}\right],
$$

which follows from equations (20) and (21) evaluated at time $t+1$. The same procedure is used in the expressions for $R_{t+1}^{H}$ and $R_{t+1}^{J}$. In the expression for $R_{t+1}^{*}$, we have substituted in $\left(y_{t+1}^{*}+1\right) / y_{t}^{*}=\beta^{-1} \exp \left[-(1-\alpha) x_{t+1}\right]$ from the nonlinear law of motion (15). The terms $z_{t+1}^{I} / E_{t}\left(z_{t+1}^{I} \mid I_{t}\right)$ for $I_{t}=G_{t}, H_{t}$ or $J_{t}$, represent the investor's proportional forecast errors under the respective information sets. By definition, forecast errors are absent for information set $I_{t}^{*}$.

In the appendix, we show that the laws of motion for the log equity return are given by

$$
\begin{aligned}
& \log \left(R_{t+1}^{G}\right)-E\left[\log \left(R_{t+1}^{G}\right)\right]=\alpha\left(x_{t+1}-\mu\right)+g_{1}\left[x_{t+1}-E_{t}\left(\tau_{x, t+1} \mid G_{t}\right)\right] \\
& \log \left(R_{t+1}^{H}\right)-E\left[\log \left(R_{t+1}^{H}\right)\right]=\alpha\left(\tau_{x, t+1}-\mu\right)+h_{1} \varepsilon_{t+1}+v_{t+1} \\
& \log \left(R_{t+1}^{J}\right)-E\left[\log \left(R_{t+1}^{J}\right)\right]=\left(1-h_{1}+\rho n_{1}\right)\left(\tau_{x, t+1}-\mu\right)+\alpha v_{t+1}+n_{1} \varepsilon_{t+2}+n_{2} v_{t+2}, \\
& \log \left(R_{t+1}^{*}\right)-E\left[\log \left(R_{t+1}^{*}\right)\right]=\alpha\left(\tau_{x, t+1}-\mu\right)+\alpha v_{t+1},
\end{aligned}
$$

where $E_{t}\left(\tau_{x, t+1} \mid G_{t}\right) \equiv \bar{x}_{t}$ is the Kalman filter estimate of trend growth from equation (17). In equation (38), $n_{1} \equiv h_{0} h_{1} /\left(1+h_{0}\right)$ and $n_{2} \equiv h_{0} h_{2} /\left(1+h_{0}\right)$ are Taylor series coefficients. ${ }^{20}$ Notice that the laws of motion for the log return all exhibit the same basic structure, i.e., a term related to dividend growth at time $t+1$ followed by terms involving a forecast error or shock innovation.

Given the laws of motion for log returns, it is straightforward to compute the following unconditional variances:

$$
\begin{aligned}
& \operatorname{Var}\left[\log \left(R_{t+1}^{G}\right)\right]=\left(\alpha+g_{1}\right)^{2} \operatorname{Var}\left(x_{t}\right)+\left(g_{1}\right)^{2} \operatorname{Var}\left(\bar{x}_{t}\right)-2 g_{1}\left(g_{1}+\alpha\right) \operatorname{Cov}\left(x_{t}, \bar{x}_{t-1}\right) \\
& \operatorname{Var}\left[\log \left(R_{t+1}^{H}\right)\right]=\alpha^{2} \operatorname{Var}\left(\tau_{x, t}\right)+h_{1}\left(h_{1}+2 \alpha\right) \sigma_{\varepsilon}^{2}+\sigma_{v}^{2} \\
& \operatorname{Var}\left[\log \left(R_{t+1}^{J}\right)\right]=\left(1-h_{1}+\rho n_{1}\right)^{2} \operatorname{Var}\left(\tau_{x, t}\right)+\left(n_{1}\right)^{2} \sigma_{\varepsilon}^{2}+\left[\left(n_{2}\right)^{2}+\alpha^{2}\right] \sigma_{v}^{2} \\
& \operatorname{Var}\left[\log \left(R_{t+1}^{*}\right)\right]=\alpha^{2} \operatorname{Var}\left(\tau_{x, t}\right)+\alpha^{2} \sigma_{v}^{2}
\end{aligned}
$$

\footnotetext{
${ }^{20}$ As described in Appendix C.2, these Taylor series coefficients arise when the term $\log \left(z_{t+2}^{H}+1\right)$ is approximated as a linear function of $\tau_{x, t+2}$ and $v_{t+2}$. The accuracy is similar to that of approximating $\log \left(z_{t}^{H}\right)$ as a linear function of $\tau_{x, t}$ and $v_{t}$ in Proposition 2. See footnote 7 for additional remarks on the accuracy of the log-linear approximations.
} 
where the details are contained in the appendix.

\subsection{Results for Special Cases}

In the special case of $\log$ utility, we have $\alpha=1$ such that $g_{1}, h_{1}, n_{1}$, and $n_{2}$ are all zero. This case yields

$$
\underbrace{\operatorname{Var}\left[\log \left(R_{t+1}^{*}\right)\right]}_{=\operatorname{Var}\left(x_{t}\right)}=\underbrace{\operatorname{Var}\left[\log \left(R_{t+1}^{J}\right)\right]}_{=\operatorname{Var}\left(x_{t}\right)}=\underbrace{\operatorname{Var}\left[\log \left(R_{t+1}^{H}\right)\right]}_{=\operatorname{Var}\left(x_{t}\right)}=\underbrace{\operatorname{Var}\left[\log \left(R_{t+1}^{G}\right)\right]}_{=\operatorname{Var}\left(x_{t}\right)}, \quad(\alpha=1),
$$

where $\operatorname{Var}\left(x_{t}\right)=\operatorname{Var}\left(\tau_{x, t}\right)+\sigma_{v}^{2}$. Since the price-dividend ratio is constant under log utility regardless of the information set, return variance is driven solely by the variance of exogenous dividend growth which is the same across information sets. From this case we know that when $\alpha \neq 1$, differences in return volatility across information sets must be driven by the variance of the price-dividend ratio and its associated covariance with dividend growth.

LeRoy and Parke (1992) considered the special case of risk neutrality and NID dividend growth. Imposing $\alpha=\rho=0$ in equations (40) through (43) yields

$$
\underbrace{\operatorname{Var}\left[\log \left(R_{t+1}^{*}\right)\right]}_{=0} \leq \underbrace{\operatorname{Var}\left[\log \left(R_{t+1}^{J}\right)\right]}_{=\left(n_{1}\right)^{2}\left(\sigma_{\varepsilon}^{2}+\sigma_{v}^{2}\right)} \leq \underbrace{\operatorname{Var}\left[\log \left(R_{t+1}^{H}\right)\right]}_{=\sigma_{\varepsilon}^{2}+\sigma_{v}^{2}}=\underbrace{\operatorname{Var}\left[\log \left(R_{t+1}^{G}\right)\right]}_{=\sigma_{\varepsilon}^{2}+\sigma_{v}^{2}}, \quad(\alpha=\rho=0),
$$

where $n_{1}=h_{0} /\left(1+h_{0}\right)<1$. For this special case, the variance under perfect foresight $I_{t}^{*}$ represents a lower bound of zero. The variance under set $J_{t}$ is less than or equal to the variance under sets $H_{t}$ and $G_{t}$. These results are directly analogous to the variance bounds on arithmetic price-changes $\left(p_{t}-p_{t-1}\right)$ derived by West (1988b) and Engel (2005) under the assumption of risk neutrality. They show that the variance of arithmetic price-changes declines monotonically with more information about future dividends. Drawing on these results, Engel (2013, p.11), states that "...the variance of changes in the asset price falls with more information..." In our more realistic setting with risk aversion and exponentially growing dividends, the analog to arithmetic price-changes is either log price-changes or log returns (which behave similarly). Hence, it is straightforward to show that Engel's statement does not hold in our setting.

Consider the following counterexample to Engel's statement when $\rho=0$ but $\alpha \neq 0$. This case implies $g_{1}=h_{1}=1-\alpha$ and $n_{1}=n_{2}=(1-\alpha) h_{0} /\left(1+h_{0}\right)$. Imposing these values in equations (40) through (43) yields

$$
\underbrace{\operatorname{Var}\left[\log \left(R_{t+1}^{*}\right)\right]}_{=\alpha^{2}\left(\sigma_{\varepsilon}^{2}+\sigma_{v}^{2}\right)} \leq \underbrace{\operatorname{Var}\left[\log \left(R_{t+1}^{J}\right)\right]}_{=\left(\alpha^{2}+n_{1}^{2}\right)\left(\sigma_{\varepsilon}^{2}+\sigma_{v}^{2}\right)} \lesseqgtr \underbrace{\operatorname{Var}\left[\log \left(R_{t+1}^{H}\right)\right]}_{=\sigma_{\varepsilon}^{2}+\sigma_{v}^{2}}=\underbrace{\operatorname{Var}\left[\log \left(R_{t+1}^{G}\right)\right]}_{=\sigma_{\varepsilon}^{2}+\sigma_{v}^{2}}, \quad(\rho=0),
$$

where the direction of the second inequality now depends on the magnitude of $\alpha$ and $n_{1}$. 
Starting from information set $H_{t}$, an increase in investor information (moving to set $J_{t}$ ) can either increase or decrease the log return variance, depending on parameter values. ${ }^{21}$

Going back to equations (41) and (43), let us consider another special case without noise shocks, such that $\sigma_{v}^{2}=0$. Now the equality of $\operatorname{Var}\left[\log \left(R_{t+1}^{H}\right)\right]$ and $\operatorname{Var}\left[\log \left(R_{t+1}^{*}\right)\right]$ can occur under two circumstances: when $\alpha=1$ and when $h_{1}+2 \alpha=0$. The critical value of $\alpha$ where $h_{1}+2 \alpha=0$ defines a second crossing point where the size ordering between $\operatorname{Var}\left[\log \left(R_{t+1}^{H}\right)\right]$ and $\operatorname{Var}\left[\log \left(R_{t+1}^{*}\right)\right]$ again reverses. Consequently, $\operatorname{Var}\left[\log \left(R_{t+1}^{*}\right)\right]$ cannot be a lower bound because it may be greater than or less than $\operatorname{Var}\left[\log \left(R_{t+1}^{H}\right)\right]$ depending on the value of $\alpha$. The second crossing point occurs at $\alpha \simeq 1 /(2 \rho \beta-1) \cdot{ }^{22}$ Positivity of $\alpha$ at the second crossing point requires that the model parameters satisfy $\rho \beta \gtrsim 0.5$.

The intuition for the ambiguous variance ordering for log returns is linked to the discounting mechanism. The parameters $\rho, \beta$, and $\alpha$ all affect the degree to which future dividend innovations influence the perfect foresight price $p_{t}^{*}$ via discounting from the future to the present. When dividends are sufficiently persistent and the investor's discount factor is sufficiently close to unity such that $\rho \beta \gtrsim 0.5$, the discounting weights applied to successive future dividend innovations decay more gradually. Since log returns are nearly the same as log price-changes, computation of the log return tends to "difference out" the future dividend innovations, thus shrinking the magnitude of $\operatorname{Var}\left[\log \left(R_{t+1}^{*}\right)\right]$ relative to the other information sets. In contrast, when $\rho \beta \lesssim 0.5$, the discounting weights applied to successive future dividend innovations decay more rapidly, so these terms do not tend to difference out in the $\log$ return computation, thus magnifying $\operatorname{Var}\left[\log \left(R_{t+1}^{*}\right)\right]$ relative to the other information sets.

The foregoing results demonstrate that the directional relationship between investor information and the volatility of log returns (or log price-changes) depends on parameter values.

\subsection{Excess Return on Equity}

We now consider the volatility of the excess return on equity, i.e., the equity premium. In the appendix, we show that the laws of motion for the log risk-free rate under each information

\footnotetext{
${ }^{21}$ Lansing (2014) shows that the analogous variance relationship involving log price changes (rather than $\log$ returns) also depends on parameter values. Moreover, he shows that the arithmetic price-change variance bounds derived by West (1988b) and Engel (2005) for the case of risk-neutrality and "cum-dividend" equity prices do not generally extend to the standard case of ex-dividend prices.

${ }^{22}$ Solving for the value of $\alpha$ where $h_{1}+2 \alpha=0$ is accomplished using an approximate expression for the solution coefficient $h_{1}$ which is given by $h_{1} \simeq(1-\alpha) /(1-\rho \beta)$. The approximate expression holds exactly when $\alpha=1$ and remains reasonably accurate for $\alpha \leq 10$.
} 
set are given by

$$
\begin{aligned}
& \log \left(R_{t+1}^{f, G}\right)-E\left[\log \left(R_{t+1}^{f, G}\right)\right]=\alpha\left[E_{t}\left(\tau_{x, t+1} \mid G_{t}\right)-\mu\right], \\
& \log \left(R_{t+1}^{f, H}\right)-E\left[\log \left(R_{t+1}^{f, H}\right)\right]=\alpha \rho\left(\tau_{x, t}-\mu\right), \\
& \log \left(R_{t+1}^{f, J}\right)-E\left[\log \left(R_{t+1}^{f, J}\right)\right]=\alpha\left(\tau_{x, t+1}-\mu\right)+\alpha v_{t+1}, \\
& \log \left(R_{t+1}^{f, *}\right)-E\left[\log \left(R_{t+1}^{f, *}\right)\right]=\alpha\left(\tau_{x, t+1}-\mu\right)+\alpha v_{t+1},
\end{aligned}
$$

where $E_{t}\left(\tau_{x, t+1} \mid G_{t}\right) \equiv \bar{x}_{t}$ is the investor's forecast of unobservable trend dividend growth. For information set $H_{t}$, the term $\rho \tau_{x, t}$ is the investor's forecast of observable trend dividend growth. Under information sets $J_{t}$ and $I_{t}^{*}$, the investor can see dividend growth at time $t+1$ without error, so no forecast is necessary.

Subtracting the risk-free rate equations from the corresponding equity returns given by equations (36) through (39) yields the following laws of motion for the log equity premium under each information set:

$$
\begin{aligned}
e p_{t+1}^{G}= & \left(\alpha+g_{1}\right)\left[x_{t+1}-E_{t}\left(\tau_{x, t+1} \mid G_{t}\right)\right]+\frac{1}{2}\left[\alpha^{2}-\left(g_{1}\right)^{2}\right]\left(\sigma_{\varepsilon}^{2}+\sigma_{v}^{2}\right), \\
e p_{t+1}^{H}= & \left(\alpha+h_{1}\right) \varepsilon_{t+1}+v_{t+1}+\frac{1}{2}\left[\alpha^{2}-\left(h_{1}\right)^{2}\right] \sigma_{\varepsilon}^{2}+\frac{1}{2}\left[\alpha^{2}-\left(h_{2}\right)^{2}\right] \sigma_{v}^{2}, \\
e p_{t+1}^{J}= & {\left[\rho n_{1}+1-\left(\alpha+h_{1}\right)\right]\left(\tau_{x, t+1}-\mu\right)+n_{1} \varepsilon_{t+2}+n_{1} v_{t+2} } \\
& +\log \left\{1+\beta \exp [(1-\alpha) \mu]\left[1-\exp \left(\frac{1}{2}\left(h_{1}\right)^{2} \sigma_{\varepsilon}^{2}+\frac{1}{2}\left(h_{2}\right)^{2} \sigma_{v}^{2}\right)\right]\right\}, \\
e p_{t+1}^{*}= & 0,
\end{aligned}
$$

where $e p_{t+1}^{I} \equiv \log \left(R_{t+1}^{I} / R_{t+1}^{f, I}\right)$ for $I_{t}=G_{t}, H_{t}, J_{t}$, and $I_{t}^{*}$. The constant terms at the end of each expression give the mean equity premium, as derived in the appendix.

Equation (54) shows that the equity premium is zero under perfect foresight. This is because there is no additional risk to purchasing equity shares versus a one-period bond when all future dividends and trend growth rates are known with certainty. The perfect foresight case establishes a theoretical lower bound of zero on excess return volatility even when investors are risk averse. However, equations (51), (52), and (53) imply that an increase in information about dividends can either increase or decrease the volatility of excess returns, depending on parameter values. Similar to the results for equity returns, the relationship between the variance of the equity premium and investor information can be non-monotonic. 
In the special case when $\rho=0$ but $\alpha \neq 0$, we have $g_{1}=h_{1}=1-\alpha$ and $n_{1}=n_{2}=$ $(1-\alpha) h_{0} /\left(1+h_{0}\right)$. Imposing these values in equations (51) through (54) and then computing the unconditional variance in each case yields

$$
\underbrace{\operatorname{Var}\left(e p_{t+1}^{*}\right)}_{=0} \leq \underbrace{\operatorname{Var}\left(e p_{t+1}^{J}\right)}_{=\left(n_{1}\right)^{2}\left(\sigma_{\varepsilon}^{2}+\sigma_{v}^{2}\right)} \lesseqgtr \underbrace{\operatorname{Var}\left(e p_{t+1}^{H}\right)}_{=\sigma_{\varepsilon}^{2}+\sigma_{v}^{2}}=\underbrace{\left.\operatorname{Var}\left(e p_{t+1}^{G}\right)\right]}_{=\sigma_{\varepsilon}^{2}+\sigma_{v}^{2}}, \quad(\rho=0),
$$

which is similar, but not identical, to the analogous special case (46) for return variance. It is straightforward to show that $\left(n_{1}\right)^{2}<1$ over the range $0<\alpha<2+1 / h_{0}$, whereas $\left(n_{1}\right)^{2}>1$ whenever $\alpha>2+1 / h_{0}$. For lower levels of risk aversion, providing investors with information about $d_{t+1}$ and $\tau_{x, t+1}$ (moving from information set $H_{t}$ to $J_{t}$ ) reduces excess return variance such that $\operatorname{Var}\left(e p_{t+1}^{J}\right)<\operatorname{Var}\left(e p_{t+1}^{H}\right)$. But for higher levels of risk aversion, providing the same information increases excess return variance such that the variance inequality is reversed.

\subsection{Quantitative Analysis}

Figures 2 and 3 show how the coefficient of relative risk aversion affects return volatility and excess return volatility under each of the four informations sets. As in Figure 1, the standard deviation of consumption growth is held constant across information sets to match the data. In each figure, the top panel shows the results for the baseline calibration while the bottom panel shows the results for the higher noise calibration. The horizontal dashed lines at $17.1 \%$ (Figure 2) and $17.4 \%$ (Figure 3) show the corresponding standard deviations in U.S. data for the period 1871 to $2012 .^{23}$

Figure 2 shows that equity return volatility is U-shaped with respect to $\alpha$ for information sets $G_{t}, H_{t}$, and $J_{t}$. In contrast, return volatility is linear in $\alpha$ under set $I_{t}^{*}$. All four lines intersect at $\alpha=1$, consistent with the theoretical result (44). When $\alpha<1$, the return volatility is lowest under set $I_{t}^{*}$ and highest under set $G_{t}$. However, when $\alpha>1$, the size ordering of the four return volatilities is different, with set $J_{t}$ now exhibiting the highest volatility. Moreover, under the higher noise calibration (lower panel), the volatility lines can cross at two different values of $\alpha$, implying reversals in the size ordering at the crossing point. For example, return volatility under sets $H_{t}$ and $I_{t}^{*}$ are equal at $\alpha=1$ and $\alpha=2.4$. The second crossing point is close to the value $\alpha \simeq 1 /(2 \rho \beta-1)$ predicted earlier for the special case when $\sigma_{v}^{2}=0$.

[Figure 2 about here]

In Figure 3, excess return volatility is U-shaped for information set $H_{t}$ but V-shaped for information sets $G_{t}$ and $J_{t}$. The $\mathrm{V}$-shape implies a unique value of $\alpha$ that makes excess

\footnotetext{
${ }^{23}$ The U.S. real return data are from Robert Shiller's website. The proxy for the risk free rate is the one-year real interest rate.
} 
return volatility equal to zero. Under set $G_{t}$, for example, equation (51) shows that excess return volatility is zero when the condition $\alpha=-g_{1}$ is satisfied, where $g_{1}$ depends on $\alpha$ via the expression in Proposition 1. Veronesi (2000) obtains a similar result in a model with imperfect information about mean dividend growth. Specifically, he shows (Proposition 4, p. 819) that the conditional variance of excess returns on equity is a U-shaped function of the risk aversion coefficient.

[Figure 3 about here]

Both Figures 2 and 3 show that model-predicted volatility for equity returns and excess returns can match the data for $\alpha \leq 10$. As in Figure 1, concrete knowledge about investor information and the values of $\alpha$ and $\sigma_{\varepsilon} / \sigma_{v}$ is needed before one can make a finding of excess volatility in the data.

\section{Signal-to-Noise Ratio and Risk Aversion}

As the final part of our quantitative analysis, Figure 4 shows how the signal-to-noise ratio $\sigma_{\varepsilon} / \sigma_{v}$ and the coefficient of relative risk aversion $\alpha$ affect the standard deviations of equity market variables when trend dividend growth is unobservable (information set $G_{t}$ ). Going from left to right in each panel, we increase $\sigma_{\varepsilon} / \sigma_{v}$ while holding $\operatorname{Var}\left(x_{t}\right)$ and $\operatorname{Corr}\left(x_{t}, x_{t-1}\right)$ constant at the U.S. data values shown in Table 1. As $\sigma_{\varepsilon} / \sigma_{v}$ increases, the model requires a higher value for the trend growth persistence parameter $\rho$ to maintain $\operatorname{Corr}\left(x_{t}, x_{t-1}\right)=0.50$ as in the data. ${ }^{24}$ The top left panel plots the calibrated value of $\rho$ as a function of $\sigma_{\varepsilon} / \sigma_{v}$.

[Figure 4 about here]

As $\sigma_{\varepsilon} / \sigma_{v} \rightarrow 0$, the calibration procedure requires $\rho \rightarrow 1$. As trend growth comes more persistent, the standard deviations of the equity market variables tend to be magnified. However, an interesting feature is that the standard deviation of the equity return (lower left panel) and the standard deviation of the excess return (lower right panel) are both hump-shaped functions of $\sigma_{\varepsilon} / \sigma_{v}$. As $\sigma_{\varepsilon} / \sigma_{v}$ starts increasing from around zero, the calibrated value of $\rho$ remains close to unity so that return volatility initially goes up. But as $\sigma_{\varepsilon} / \sigma_{v}$ continues to increase, the calibrated value of $\rho$ drops more rapidly, causing return volatility to go down.

When $\alpha=5$, the model can roughly match the standard deviations in the data when $\sigma_{\varepsilon} / \sigma_{v} \simeq 0.36$ and $\rho \simeq 0.94$. However, these same values imply $\operatorname{Corr}\left(x_{t}, x_{t-2}\right)=0.47$ and $\operatorname{Corr}\left(\Delta x_{t}, \Delta x_{t-1}\right)=-0.47$ which compare less favorably to the corresponding U.S. data correlations of 0.19 and -0.21 , respectively. Still, given the range of uncertainty surrounding

\footnotetext{
${ }^{24}$ Using equation (A.13) in the appendix, the calibrated value of $\rho$ is the positive root of the quadratic equation $a \rho^{2}+b \rho+c=0$, where $a=0.50, b=\left(\sigma_{\varepsilon} / \sigma_{v}\right)^{2}$, and $c=-0.50\left[1+\left(\sigma_{\varepsilon} / \sigma_{v}\right)^{2}\right]$.
} 
the persistence properties of U.S. consumption growth, our results show that a plausiblycalibrated asset pricing model can roughly match the observed volatility of the equity market data. $^{25}$

\section{Conclusion}

This paper showed that providing investors with more information about the dividend process will monotonically increase the volatility of the log price-dividend ratio. In contrast, providing investors with more information can either increase or decrease the volatility of the log equity return (or log price-change). The directional impact of information on return volatility depends crucially on parameter values that influence the investor's discounting mechanism. These include the coefficient of relative risk aversion and the persistence parameter for trend dividend growth. Both parameters affect the degree to which future dividend innovations tend to "difference out" when computing equity returns, excess returns, or log-price changes.

Studies by West (1988b) and Engel (2005) had previously established a monotonic, declining relationship between arithmetic price-change volatility and investor information, assuming risk neutral investors. Our results show that their findings do not extend to a setting with risk aversion and exponentially-growing dividends, except in some special cases. This result is important because it means that news about future dividends can help account for the high variance of asset price changes in the data.

A finding of excess volatility in the data relative to the model's theoretical prediction requires knowledge of at least three things: (1) the information set used by investors to make conditional forecasts, including whether they have some news about future dividends, (2) investors' level of risk aversion, and (3) the amount of noise present in the dividend process. Without this knowledge, it becomes difficult to conclude that that the observed volatility in the data is excessive.

\footnotetext{
${ }^{25}$ Otrok, Ravikumar, and Whiteman (2002) document the time-varying persistence properties of U.S. consumption growth.
} 


\section{Appendix}

\section{A Solution: Information Set $G_{t}$}

\section{A.1 Proof of Proposition 1}

The conjectured solution in Proposition 1 implies that $z_{t}^{G}$ is log-normally distributed. To evaluate the conditional expectation that appears in the equilibrium condition (21), we make use of the properties of the conditional log normal distribution. Specifically, we iterate the conjectured law of motion for $z_{t}^{G}$ ahead one period, take logarithms, and then compute the conditional mean and the conditional variance as follows:

$$
E_{t}\left(z_{t+1}^{G} \mid G_{t}\right)=\exp \left\{E_{t}\left[\log \left(z_{t+1}^{G}\right) \mid G_{t}\right]+\frac{1}{2} \operatorname{Var}_{t}\left[\log \left(z_{t+1}^{G}\right) \mid G_{t}\right]\right\}
$$

where

$$
\begin{aligned}
E_{t}\left[\log \left(z_{t+1}^{G}\right) \mid G_{t}\right] & =g_{0}+E_{t}\left[g_{1}\left(x_{t+1}-\mu\right) \mid G_{t}\right]+g_{2}\left(\bar{x}_{t}-\mu\right), \\
& =g_{0}+\left(g_{1}+g_{2}\right)\left(\bar{x}_{t}-\mu\right), \\
& =g_{0}+\left(g_{1}+g_{2}\right)\left[\rho \lambda\left(x_{t}-\mu\right)+\rho(1-\lambda)\left(\bar{x}_{t-1}-\mu\right)\right], \\
\operatorname{Var}_{t}\left[\log \left(z_{t+1}^{G}\right) \mid G_{t}\right] & =\operatorname{Var}_{t}\left(g_{1} x_{t+1} \mid G_{t}\right), \\
& =\operatorname{Var}_{t}\left\{g_{1}\left[\rho \tau_{x, t}+(1-\rho) \mu+\varepsilon_{t+1}+v_{t+1}\right] \mid G_{t}\right\}, \\
& =\left(g_{1}\right)^{2}\left(\sigma_{\varepsilon}^{2}+\sigma_{v}^{2}\right),
\end{aligned}
$$

where we employ the laws of motion for dividend growth (5) and (6). The investor's forecast for dividend growth is given by $E_{t}\left(x_{t+1} \mid G_{t}\right)=E_{t}\left(\tau_{x, t+1} \mid G_{t}\right) \equiv \bar{x}_{t}$, where $\bar{x}_{t}$ evolves according to Kalman filter updating equation (17). Substituting (A.2) and (A.3) into (A.1) yields an expression for $E_{t}\left(z_{t+1}^{G} \mid G_{t}\right)$, which we then substitute into the right side of the equilibrium condition (21). Taking logarithms of both sides of the resulting expression yields

$$
\begin{aligned}
\log \left(z_{t}^{G}\right)=F\left(x_{t}, \bar{x}_{t-1}\right)= & \log (\beta)+(1-\alpha) x_{t}+\log \left\{g _ { 0 } \operatorname { e x p } \left[\left(g_{1}+g_{2}\right) \rho \lambda\left(x_{t}-\mu\right)\right.\right. \\
& \left.\left.+\left(g_{1}+g_{2}\right) \rho(1-\lambda)\left(\bar{x}_{t-1}-\mu\right)+\frac{1}{2}\left(g_{1}\right)^{2}\left(\sigma_{\varepsilon}^{2}+\sigma_{v}^{2}\right)\right]+1\right\} \\
\simeq & \log \left(g_{0}\right)+g_{1}\left(x_{t}-\mu\right)+g_{2}\left(\bar{x}_{t-1}-\mu\right),
\end{aligned}
$$


where the Taylor-series coefficients $g_{0}, g_{1}$, and $g_{2}$ are given by

$$
\begin{aligned}
\log \left(g_{0}\right) & =F(\mu, \mu)=\log (\beta)+(1-\alpha) \mu+\log \left\{g_{0} \exp \left[\frac{1}{2}\left(g_{1}\right)^{2}\left(\sigma_{\varepsilon}^{2}+\sigma_{v}^{2}\right)\right]+1\right\} \\
g_{1} & =\left.\frac{\partial F}{\partial x_{t}}\right|_{\mu, \mu}=1-\alpha+\frac{g_{0}\left(g_{1}+g_{2}\right) \rho \lambda \exp \left[\frac{1}{2}\left(g_{1}\right)^{2}\left(\sigma_{\varepsilon}^{2}+\sigma_{v}^{2}\right)\right]}{g_{0} \exp \left[\frac{1}{2}\left(g_{1}\right)^{2}\left(\sigma_{\varepsilon}^{2}+\sigma_{v}^{2}\right)\right]+1} \\
g_{2} & =\left.\frac{\partial F}{\partial \bar{x}_{t-1}}\right|_{\mu, \mu}=1-\alpha+\frac{g_{0}\left(g_{1}+g_{2}\right) \rho(1-\lambda) \exp \left[\frac{1}{2}\left(g_{1}\right)^{2}\left(\sigma_{\varepsilon}^{2}+\sigma_{v}^{2}\right)\right]}{g_{0} \exp \left[\frac{1}{2}\left(g_{1}\right)^{2}\left(\sigma_{\varepsilon}^{2}+\sigma_{v}^{2}\right)\right]+1}
\end{aligned}
$$

Solving (A.5) through (A.7) for $g_{0}, g_{1}$, and $g_{2}$ yields the expressions shown in Proposition 1. Equation (A.6) reduces to the following nonlinear equation that determines $g_{1}$ :

$$
g_{1}=1-\alpha+\left[g_{1}-(1-\alpha)(1-\lambda)\right] \rho \beta \exp \left[(1-\alpha) \mu+\frac{1}{2}\left(g_{1}^{2}\right)\left(\sigma_{\varepsilon}^{2}+\sigma_{v}^{2}\right)\right] .
$$

There are two solutions, but only one satisfies the inequality condition in Proposition 1, which is verified after solving for $g_{1}$ using a nonlinear equation solver.

\section{A.2 Asset Pricing Moments}

This section outlines the derivation of equations (23) and (40). Taking the unconditional expectation of $\log \left(y_{t}^{G}\right)$ in equation (22) yields

$$
\begin{aligned}
& E\left[\log \left(y_{t}^{G}\right)\right]=\log \left(g_{0}\right)+\frac{1}{2}\left(g_{1}\right)^{2}\left(\sigma_{\varepsilon}^{2}+\sigma_{v}^{2}\right), \\
& \log \left(y_{t}^{G}\right)-E\left[\log \left(y_{t}^{G}\right)\right]=\left(g_{1}+g_{2}\right)\left(\bar{x}_{t}-\mu\right),
\end{aligned}
$$

which in turn implies the variance expression (23). Equation (A.9) is used to calibrate the value of $\beta$, as discussed in section 3.5.

Straightforward computations using the laws of motion (5), (6), and (17) yield

$$
\begin{aligned}
& \operatorname{Var}\left(x_{t}\right)=\operatorname{Var}\left(\tau_{x, t}\right)+\sigma_{v}^{2}, \\
& \operatorname{Var}\left(\tau_{x, t}\right)=\sigma_{\varepsilon}^{2} /\left(1-\rho^{2}\right) \\
& \operatorname{Corr}\left(x_{t}, x_{t-1}\right)=\frac{\rho\left(\sigma_{\varepsilon} / \sigma_{v}\right)^{2}}{\left(\sigma_{\varepsilon} / \sigma_{v}\right)^{2}+1-\rho^{2}}, \\
& \operatorname{Cov}\left(x_{t}, \bar{x}_{t-1}\right)=\frac{\rho^{2} \lambda \operatorname{Var}\left(\tau_{x, t}\right)}{\left[1-\rho^{2}(1-\lambda)\right]} \\
& \operatorname{Var}\left(\bar{x}_{t}\right)=\frac{\rho^{2} \lambda^{2} \operatorname{Var}\left(x_{t}\right)+2 \rho^{2} \lambda(1-\lambda) \operatorname{Cov}\left(x_{t}, \bar{x}_{t-1}\right)}{1-\rho^{2}(1-\lambda)^{2}},
\end{aligned}
$$


where $\lambda$ is given by equation (18).

As described in the text, the equity return (31) implied by information set $G_{t}$ can be written as

$$
R_{t+1}^{G}=\beta^{-1} \exp \left(\alpha x_{t+1}\right)\left[\frac{z_{t+1}^{G}}{E_{t}\left(z_{t+1} \mid G_{t}\right)}\right] .
$$

Substituting in $E_{t}\left(z_{t+1}^{G} \mid G_{t}\right)$ from equation (A.1) through (A.3) and the solution for $z_{t+1}^{G}$ implied by Proposition 1 and then taking the unconditional mean of $\log \left(R_{t+1}^{G}\right)$ yields

$$
E\left[\log \left(R_{t+1}^{G}\right)\right]=-\log (\beta)+\alpha \mu-\frac{1}{2}\left(g_{1}\right)^{2}\left(\sigma_{\varepsilon}^{2}+\sigma_{v}^{2}\right) .
$$

We then have

$$
\begin{aligned}
\log \left(R_{t+1}^{G}\right)-E\left[\log \left(R_{t+1}^{G}\right)\right] & =\left(\alpha+g_{1}\right)\left(x_{t+1}-\mu\right)-g_{1} \rho \lambda\left(x_{t}-\mu\right)-g_{1} \rho(1-\lambda)\left(\bar{x}_{t-1}-\mu\right), \\
& =\left(\alpha+g_{1}\right)\left(x_{t+1}-\mu\right)-g_{1}\left[E_{t}\left(\tau_{x, t+1} \mid G_{t}\right)-\mu\right], \\
& =\alpha\left(x_{t+1}-\mu\right)+g_{1}\left[x_{t+1}-E_{t}\left(\tau_{x, t+1} \mid G_{t}\right)\right],
\end{aligned}
$$

where terms involving $g_{2}$ cancel out and we make use of the Kalman filter updating equation (17). Squaring both sides of equation (A.18) and then taking the unconditional mean yields the expression for $\operatorname{Var}\left[\log \left(R_{t+1}^{G}\right)\right]$ in equation (40).

The risk free rate is determined by the following first-order condition

$$
R_{t+1}^{f, G}=\frac{1}{E_{t}\left[\beta\left(c_{t+1} / c_{t}\right)^{-\alpha} \mid G_{t}\right]}=\frac{1}{E_{t}\left(z_{t+1}^{f, G} \mid G_{t}\right)},
$$

where we define $z_{t+1}^{f, G} \equiv \beta \exp \left(x_{t+1}\right)^{-\alpha}$ as the object to be forecasted. Again making use of the properties of the conditional log normal distribution, we have

$$
E_{t}\left(z_{t+1}^{f, G} \mid G_{t}\right)=\exp \left\{E_{t}\left[\log \left(z_{t+1}^{f, G}\right) \mid G_{t}\right]+\frac{1}{2} \operatorname{Var}_{t}\left[\log \left(z_{t+1}^{f, G}\right) \mid G_{t}\right]\right\}
$$

where $\log \left(z_{t+1}^{f, G}\right)=\log \beta-\alpha x_{t+1}$. Using this expression for $\log \left(z_{t+1}^{f, G}\right)$, it is straightforward to derive the following expressions for the conditional mean and the conditional variance

$$
\begin{aligned}
E_{t}\left[\log \left(z_{t+1}^{f, G}\right) \mid G_{t}\right] & =\log \beta-\alpha E_{t}\left(\tau_{x, t+1} \mid G_{t}\right), \\
\operatorname{Var}_{t}\left[\log \left(z_{t+1}^{f, G}\right) \mid G_{t}\right] & =\alpha^{2}\left(\sigma_{\varepsilon}^{2}+\sigma_{v}^{2}\right) .
\end{aligned}
$$

Substituting (A.21) and (A.22) into (A.20) yields an expression for $E_{t}\left(z_{t+1}^{f, G}\right)$, which is substituted into the right side of the first-order condition (A.19). Taking logarithms of both sides of (A.20) yields the law of motion for $\log \left(R_{t+1}^{f, G}\right)$, which implies the following expressions

$$
\begin{aligned}
& E\left[\log \left(R_{t+1}^{f, G}\right)\right]=-\log (\beta)+\alpha \mu-\frac{1}{2} \alpha^{2}\left(\sigma_{\varepsilon}^{2}+\sigma_{v}^{2}\right), \\
& \log \left(R_{t+1}^{f, G}\right)-E\left[\log \left(R_{t+1}^{f, G}\right)\right]=\alpha\left[E_{t}\left(\tau_{x, t+1} \mid G_{t}\right)-\mu\right]
\end{aligned}
$$

where $E_{t}\left(\tau_{x, t+1} \mid G_{t}\right) \equiv \bar{x}_{t}$ is the Kalman filter estimate of trend growth from equation (17). 


\section{B Solution: Information Set $H_{t}$}

\section{B.1 Proof of Proposition 2}

Iterating ahead the conjectured law of motion for $z_{t}^{H}$ and taking the conditional expectation implied by the information set $H_{t}$ yields

$$
\begin{aligned}
E_{t}\left(z_{t+1}^{H} \mid H_{t}\right) & =E_{t}\left\{h_{0} \exp \left[h_{1} \rho\left(\tau_{x, t}-\mu\right)+h_{1} \varepsilon_{t+1}+h_{2} v_{t+1}\right] \mid H_{t}\right\} . \\
& =h_{0} \exp \left[h_{1} \rho\left(\tau_{x, t}-\mu\right)+\frac{1}{2}\left(h_{1}\right)^{2} \sigma_{\varepsilon}^{2}+\frac{1}{2}\left(h_{2}\right)^{2} \sigma_{v}^{2}\right] .
\end{aligned}
$$

Substituting the above expression into the $H_{t}$ version of the first-order condition (21) and then taking logarithms yields

$$
\begin{aligned}
\log \left(z_{t}^{H}\right)=F\left(\tau_{x, t}, v_{t}\right),= & \log (\beta)+(1-\alpha)\left(\tau_{x, t}+v_{t}\right) \\
& +\log \left\{h_{0} \exp \left[h_{1} \rho\left(\tau_{x, t}-\mu\right)+\frac{1}{2}\left(h_{1}\right)^{2} \sigma_{\varepsilon}^{2}+\frac{1}{2}\left(h_{2}\right)^{2} \sigma_{v}^{2}\right]+1\right\} \\
\simeq & \log \left(h_{0}\right)+h_{1}\left(\tau_{x, t}-\mu\right)+h_{2} v_{t}
\end{aligned}
$$

where the Taylor-series coefficients $h_{0}, h_{1}$, and $h_{2}$ are given by

$$
\begin{aligned}
\log \left(h_{0}\right) & =F(\mu, 0)=\log (\beta)+(1-\alpha) \mu+\log \left\{h_{0} \exp \left[\frac{1}{2}\left(h_{1}\right)^{2} \sigma_{\varepsilon}^{2}+\frac{1}{2}\left(h_{2}\right)^{2} \sigma_{v}^{2}\right]+1\right\} \\
h_{1} & =\left.\frac{\partial F}{\partial \tau_{x, t}}\right|_{\mu, 0}=1-\alpha+\frac{h_{0} h_{1} \rho \exp \left[\frac{1}{2}\left(h_{1}\right)^{2} \sigma_{\varepsilon}^{2}+\frac{1}{2}\left(h_{2}\right)^{2} \sigma_{v}^{2}\right]}{h_{0} \exp \left[\frac{1}{2}\left(h_{1}\right)^{2} \sigma_{\varepsilon}^{2}+\frac{1}{2}\left(h_{2}\right)^{2} \sigma_{v}^{2}\right]+1} . \\
h_{2} & =\left.\frac{\partial F}{\partial v_{t}}\right|_{\mu, 0}=1-\alpha
\end{aligned}
$$

Solving (B.3) through (B.5) for $h_{0}, h_{1}$, and $h_{2}$ yields the expressions shown in Proposition 2. Equation (B.4) reduces to the following nonlinear equation that determines $h_{1}$ :

$$
h_{1}=1-\alpha+h_{1} \rho \beta \exp \left[(1-\alpha) \mu+\frac{1}{2}\left(h_{1}^{2}\right) \sigma_{\varepsilon}^{2}+\frac{1}{2}(1-\alpha)^{2} \sigma_{v}^{2}\right],
$$

where we have substituted $h_{2}=1-\alpha$. There are two solutions, but only one satisfies the inequality condition in Proposition 2, which is verified after solving for $h_{1}$ using a nonlinear equation solver.

\section{B.2 Asset Pricing Moments}

This section briefly outlines the derivation of equations (25) and (41). Starting from equation (24) and taking the unconditional expectation of $\log \left(y_{t}^{H}\right)$ yields

$$
E\left[\log \left(y_{t}^{H}\right)\right]=\log \left(h_{0}\right)+\frac{1}{2}\left(h_{1}\right)^{2} \sigma_{\varepsilon}^{2}+\frac{1}{2}\left(h_{2}\right)^{2} \sigma_{v}^{2},
$$




$$
\log \left(y_{t}^{H}\right)-E\left[\log \left(y_{t}^{H}\right)\right]=h_{1} \rho\left(\tau_{x, t}-\mu\right),
$$

which in turn implies the variance expression (25).

To compute the equity return $R_{t+1}^{H}$, we substitute $E_{t}\left(z_{t+1}^{H} \mid H_{t}\right)$ from equation (B.1) and $z_{t+1}^{H}=h_{0} \exp \left[h_{1}\left(\tau_{x, t+1}-\mu\right)+h_{2} v_{t+1}\right]$ from Proposition 2 into equation (32). Taking logarithms and then computing the moments yields

$$
E\left[\log \left(R_{t+1}^{H}\right)\right]=-\log (\beta)+\alpha \mu-\frac{1}{2}\left(h_{1}\right)^{2} \sigma_{\varepsilon}^{2}-\frac{1}{2}\left(h_{2}\right)^{2} \sigma_{v}^{2} .
$$

We then have

$$
\begin{aligned}
\log \left(R_{t+1}^{H}\right)-E\left[\log \left(R_{t+1}^{H}\right)\right] & =\alpha\left(x_{t+1}-\mu\right)+h_{1}\left(\tau_{x, t+1}-\mu\right)+h_{2} v_{t+1}-h_{1} \rho\left(\tau_{x, t}-\mu\right), \\
& =\alpha\left(x_{t+1}-\mu\right)+h_{1} \varepsilon_{t+1}+h_{2} v_{t+1}, \\
& =\alpha\left(\tau_{x, t+1}-\mu\right)+h_{1} \varepsilon_{t+1}+\underbrace{\left(\alpha+h_{2}\right)}_{=1} v_{t+1},
\end{aligned}
$$

where we substitute $h_{2}=1-\alpha$. Squaring both sides of equation (B.10) and then taking the unconditional mean yields the expression for $\operatorname{Var}\left[\log \left(R_{t+1}^{H}\right)\right]$ in equation (41).

The log risk free rate is determined by the following first-order condition

$$
\begin{aligned}
\log \left(R_{t+1}^{f, H}\right) & =-\log \left\{E_{t}\left[\beta\left(c_{t+1} / c_{t}\right)^{-\alpha} \mid H_{t}\right]\right\} \\
& =-\log \left\{E_{t}\left[\beta \exp \left(-\alpha x_{t+1}\right) \mid H_{t}\right]\right\} \\
& =-\log \left\{E_{t}\left[\beta \exp \left(-\alpha \tau_{x, t+1}-\alpha v_{t+1}\right) \mid H_{t}\right]\right\} \\
& =-\log (\beta)+\alpha\left[\rho \tau_{x, t}+(1-\rho) \mu\right]-\frac{1}{2} \alpha^{2} \sigma_{\varepsilon}^{2}-\frac{1}{2} \alpha^{2} \sigma_{v}^{2}
\end{aligned}
$$

where we have inserted the laws of motion for $x_{t+1}$ and $\tau_{x, t+1}$ from equations (5) and (6) before taking the conditional expectation. Taking the unconditional mean of $\log \left(R_{t+1}^{f, H}\right)$ and then subtracting the unconditional mean from equation (B.11) yields the following expressions

$$
\begin{aligned}
& E\left[\log \left(R_{t+1}^{f, H}\right)\right]=-\log (\beta)+\alpha \mu-\frac{1}{2} \alpha^{2} \sigma_{\varepsilon}^{2}-\frac{1}{2} \alpha^{2} \sigma_{v}^{2}, \\
& \log \left(R_{t+1}^{f, G}\right)-E\left[\log \left(R_{t+1}^{f, G}\right)\right]=\alpha \rho\left(\tau_{x, t}-\mu\right) .
\end{aligned}
$$

\section{Solution: Information Set $J_{t}=H_{t} \cup\left\{d_{t+1}, \tau_{x, t+1}\right\}$}

\section{C.1 Characterizing $y_{t}^{J}$}

Imposing the equilibrium relationship $c_{t}=d_{t}$ for all $t$ in the first-order condition (3) yields

$$
p_{t}^{J}=\underbrace{\beta\left(\frac{d_{t+1}}{d_{t}}\right)^{-\alpha}}_{M_{t, t+1}}\left(d_{t+1}+p_{t+1}^{H}\right),
$$


where $x_{t+1}$ and $\tau_{x, t+1}$ are now known to the investor at time $t$. Together, these values allow the investor to compute $v_{t+1}=x_{t+1}-\tau_{x, t+1}$. Going forward from time $t+1$, the investor will be faced with information set $H_{t+1}$ where $p_{t+1}^{H}$ is the corresponding equilibrium price.

Dividing both sides of equation (C.1) by $d_{t}$ yields the following expression for $y_{t}^{J} \equiv p_{t}^{J} / d_{t}$

$$
\begin{aligned}
y_{t}^{J} & =\beta \exp \left[(1-\alpha) x_{t+1}\right]\left(1+y_{t+1}^{H}\right), \\
& =z_{t+1}^{H},
\end{aligned}
$$

were the second equality follows directly from the definition of $z_{t}^{H}$. Given that $y_{t}^{J}=z_{t+1}^{H}$ from equation (C.2) and $y_{t}^{H}=E_{t}\left(z_{t+1}^{H} \mid H_{t}\right)$ from equation (13), we then have $y_{t}^{H}=E_{t}\left(y_{t}^{J} \mid H_{t}\right)$ which implies $\operatorname{Var}\left(y_{t}^{H}\right) \leq \operatorname{Var}\left(y_{t}^{J}\right)$.

\section{C.2 Asset Pricing Moments}

This section outlines the derivation of equations (28) and (42). From equation (C.2) and the law of motion for $z_{t+1}^{H}$, we have the following law of motion for $y_{t}^{J}$

$$
y_{t}^{J}=z_{t+1}^{H}=h_{0} \exp \left[h_{1}\left(\tau_{x, t+1}-\mu\right)+h_{2} v_{t+1}\right],
$$

which implies $E\left[\log \left(y_{t}^{J}\right)\right]=\log \left(h_{0}\right)<E\left[\log \left(y_{t}^{H}\right)\right]$. Squaring both sides of equation (C.3) and then taking the unconditional mean yields $\operatorname{Var}\left[\log \left(y_{t}^{J}\right)\right]$, as shown in equation (28).

The equity return (33) under set $J_{t}$ can be rewritten as

$$
R_{t+1}^{J}=\exp \left(x_{t+1}\right)\left[\frac{z_{t+2}^{H}+1}{z_{t+1}^{H}}\right],
$$

where we have eliminated both $y_{t}^{J}$ and $y_{t+1}^{J}$ using equation (C.2). The law of motion for $z_{t+1}^{H}$ is given by equation (C.3). An approximate law of motion for $z_{t+2}^{H}+1$ is given by

$$
z_{t+2}^{H}+1=n_{0} \exp \left[n_{1}\left(\tau_{x, t+2}-\mu\right)+n_{2} v_{t+2}\right],
$$

where $n_{0}=1+h_{0}, n_{1}=h_{0} h_{1} /\left(1+h_{0}\right)$, and $n_{2}=h_{0} h_{2} /\left(1+h_{0}\right)$ are Taylor-series coefficients.

Substituting equations (C.3) and (C.5) into (C.4) and then taking the unconditional mean of $\log \left(R_{t+1}^{J}\right)$ yields

$$
\begin{aligned}
E\left[\log \left(R_{t+1}^{J}\right)\right]= & \log \left(n_{0} / h_{0}\right)+\mu \\
= & -\log (\beta)+\alpha \mu \\
& +\log \left\{1+\beta \exp [(1-\alpha) \mu]\left[1-\exp \left(\frac{1}{2}\left(h_{1}\right)^{2} \sigma_{\varepsilon}^{2}+\frac{1}{2}\left(h_{2}\right)^{2} \sigma_{v}^{2}\right)\right]\right\} .
\end{aligned}
$$

We then have

$$
\begin{aligned}
\log \left(R_{t+1}^{J}\right)-E\left[\log \left(R_{t+1}^{J}\right)\right] & =n_{1}\left(\tau_{x, t+2}-\mu\right)+\left(1-h_{1}\right)\left(\tau_{x, t+1}-\mu\right)+n_{2} v_{t+2}+\left(1-h_{2}\right) v_{t+1}, \\
& \left.=\left(1-h_{1}+\rho n_{1}\right)\left(\tau_{x, t+1}-\mu\right)+n_{1} \varepsilon_{t+2}+n_{2} v_{t+2}+\alpha v_{t+1}, \quad \text { (C. } 7\right)
\end{aligned}
$$


where we make the substitution $\tau_{x, t+2}-\mu=\rho\left(\tau_{x, t+1}-\mu\right)+\varepsilon_{t+1}$ from (6) and $1-h_{2}=\alpha$ from Proposition 2. Squaring both sides of equation (C.7) and taking the unconditional mean yields the expression for $\operatorname{Var}\left[\log \left(R_{t+1}^{J}\right)\right]$ shown in equation (42).

The log risk free rate is determined by the following first-order condition

$$
\begin{aligned}
\log \left(R_{t+1}^{f, J}\right) & =-\log \left\{E_{t}\left[\beta\left(c_{t+1} / c_{t}\right)^{-\alpha} \mid J_{t}\right]\right\}, \\
& =-\log \left[\beta \exp \left(-\alpha x_{t+1}\right)\right], \\
& =-\log (\beta)+\alpha \tau_{x, t+1}+\alpha v_{t+1},
\end{aligned}
$$

where we have inserted the law of motion for $x_{t+1}$ from equation (5). Given that $J_{t}=$ $H_{t} \cup\left\{d_{t+1}, \tau_{x, t+1}\right\}$, the investor has perfect knowledge of $\tau_{x, t+1}$ and $v_{t+1}$ at time $t$ so we may drop the conditional expectation. Taking the unconditional mean of $\log \left(R_{t+1}^{f, J}\right)$ and then subtracting the unconditional mean from equation (C.8) yields the law of motion (49).

\section{Solution: Information Set $I_{t}^{*}$}

\section{D.1 Log-linearized Law of Motion}

Taking logarithms of the nonlinear law of motion (15) yields

$$
\begin{aligned}
\log \left(y_{t}^{*}\right) & =F\left[x_{t+1}, \log \left(y_{t+1}^{*}\right)\right]=\log (\beta)+(1-\alpha) x_{t+1}+\log \left\{\exp \left[\log \left(y_{t+1}^{*}\right)\right]+1\right\} \\
& = \\
& \simeq \log \left(b_{0}\right)+b_{1}\left(x_{t+1}-\mu\right)+b_{2}\left[\log \left(y_{t+1}^{*}\right)-\log \left(b_{0}\right)\right]
\end{aligned}
$$

where $x_{t+1}=\tau_{x, t+1}+v_{t+1}$ from (5). The Taylor-series coefficients $b_{0}, b_{1}$, and $b_{2}$ are given by

$$
\begin{aligned}
\log \left(b_{0}\right) & =F\left[\mu, \log \left(b_{0}\right)\right]=\log (\beta)+(1-\alpha) \mu+\log \left[b_{0}+1\right], \\
b_{1} & =\left.\frac{\partial F}{\partial x_{t+1}}\right|_{\mu, \log \left(b_{0}\right)}=1-\alpha, \\
b_{2} & =\left.\frac{\partial F}{\partial \log \left(y_{t+1}^{*}\right)}\right|_{\mu, \log \left(b_{0}\right)}=\frac{b_{0}}{b_{0}+1} .
\end{aligned}
$$

Solving equation (D.2) for the unconditional mean $b_{0}$ yields

$$
b_{0}=\exp \left\{E\left[\log \left(y_{t}^{*}\right)\right]\right\}=\frac{\beta \exp [(1-\alpha) \mu]}{1-\beta \exp [(1-\alpha) \mu]},
$$

which can be substituted into equation (D.4) to obtain the following expression:

$$
b_{2}=\beta \exp [(1-\alpha) \mu] \text {. }
$$


Subtracting $\log \left(b_{0}\right)=E\left[\log \left(y_{t}^{*}\right)\right]$ from both sides of the approximate law of motion (D.1) and then substituting for $b_{1}$ and $b_{2}$ yields equation (29).

\section{D.2 Asset Pricing Moments}

This section outlines the derivation of equations (30) and (43). Squaring both sides of equation (29) and then taking the unconditional mean to obtain the variance yields

$$
\operatorname{Var}\left[\log \left(y_{t}^{*}\right)\right]=\frac{(1-\alpha)^{2} \operatorname{Var}\left(x_{t}\right)+2(1-\alpha) \beta \exp [(1-\alpha) \mu] \operatorname{Cov}\left[\log \left(y_{t}^{*}\right), x_{t}\right]}{1-\beta^{2} \exp [2(1-\alpha) \mu]}
$$

The next step is to compute $\operatorname{Cov}\left[\log \left(y_{t}^{*}\right), x_{t}\right]$ which appears in equation (D.7). Starting from equation (29), we have

$$
\begin{aligned}
\operatorname{Cov}\left[\log \left(y_{t}^{*}\right), x_{t}\right]= & (1-\alpha) \underbrace{\operatorname{Cov}\left(x_{t+1}, x_{t}\right)}_{=\operatorname{Cov}\left(\tau_{x, t}, \tau_{x, t-1}\right)} \\
& +\beta \exp [(1-\alpha) \mu] \operatorname{Cov}\left[\log \left(y_{t+1}^{*}\right), x_{t}\right], \\
\operatorname{Cov}\left[\log \left(y_{t+1}^{*}\right), x_{t}\right]= & (1-\alpha) \underbrace{\operatorname{Cov}\left(x_{t+2}, x_{t}\right)}_{=\rho \operatorname{Cov}\left(\tau_{x, t}, \tau_{x, t-1}\right)} \\
& +\beta \exp [(1-\alpha) \mu] \operatorname{Cov}\left[\log \left(y_{t+2}^{*}\right), x_{t}\right],
\end{aligned}
$$

and so on for $\operatorname{Cov}\left[\log \left(y_{t+j}^{*}\right), x_{t}\right], j=1,2,3, \ldots$ By repeated substitution to eliminate the term $\operatorname{Cov}\left[\log \left(y_{t+j}^{*}\right), x_{t}\right]$ and then applying a transversality condition, we obtain the following expression:

$$
\begin{aligned}
\operatorname{Cov}\left[\log \left(y_{t}^{*}\right), x_{t}\right] & =(1-\alpha) \operatorname{Cov}\left(\tau_{x, t}, \tau_{x, t-1}\right) \sum_{j=0}^{\infty}\{\rho \beta \exp [(1-\alpha) \mu]\}^{j} \\
& =\frac{(1-\alpha) \operatorname{Cov}\left(\tau_{x, t}, \tau_{x, t-1}\right)}{1-\rho \beta \exp [(1-\alpha) \mu]}=\frac{(1-\alpha) \rho \operatorname{Var}\left(\tau_{x, t}\right)}{1-\rho \beta \exp [(1-\alpha) \mu]},
\end{aligned}
$$

where the infinite sum converges provided that $\rho \beta \exp [(1-\alpha) \mu]<1$. Substituting equation (D.10) into equation (D.7) together with $\operatorname{Var}\left(x_{t}\right)$ from (A.11) and then simplifying yields equation (30).

From equation (34), the perfect foresight return can be written as

$$
\begin{aligned}
R_{t+1}^{*} & =\beta^{-1} \exp \left(\alpha x_{t+1}\right) \\
& =\beta^{-1} \exp \left[\alpha\left(\tau_{x, t+1}+v_{t+1}\right)\right]
\end{aligned}
$$


where we have substituted in $\left(y_{t+1}^{*}+1\right) / y_{t}^{*}=\beta^{-1} \exp \left[-(1-\alpha) x_{t+1}\right]$ from the exact nonlinear law of motion (15). Taking the unconditional expectation of $\log \left(R_{t+1}^{*}\right)$ yields

$$
E\left[\log \left(R_{t+1}^{*}\right)\right]=-\log (\beta)+\alpha \mu
$$

We then have

$$
\log \left(R_{t+1}^{*}\right)-E\left[\log \left(R_{t+1}^{*}\right)\right]=\alpha\left(\tau_{x, t+1}-\mu\right)+\alpha v_{t+1},
$$

which in turns implies the unconditional variance (43).

The log risk free rate is determined by the following perfect-foresight version of the firstorder condition

$$
\begin{aligned}
\log \left(R_{t+1}^{f, *}\right) & =-\log \left[\beta\left(c_{t+1} / c_{t}\right)^{-\alpha}\right], \\
& =-\log \left[\beta \exp \left(-\alpha x_{t+1}\right)\right], \\
& =-\log (\beta)+\alpha\left(\tau_{x, t+1}+v_{t+1}\right)
\end{aligned}
$$

where we have inserted the law of motion for $x_{t+1}$ from equation (5). Taking the unconditional mean of $\log \left(R_{t+1}^{f, *}\right)$ and then subtracting the unconditional mean from equation (D.14) yields equation (50). 


\section{References}

Barsky, R.B., Sims, E.R. 2011. News shocks and business cycles. Journal of Monetary Economics 58, 273-289.

Cochrane, J.H., 1992 Explaining the variance of price-dividend ratios. Review of Financial Studies 5, 243-280.

Cogley, T., Sargent, T., 2008. Anticipated utility and rational expectations as approximations of Bayesian decision making. International Economic Review 49, 185-221.

Collard, F., Juillard, M., 2001. Accuracy of stochastic perturbation methods: The case of asset pricing models. Journal of Economic Dynamics and Control 25, 979-999.

Engel, C., 2005. Some new variance bounds for asset prices. Journal of Money Credit and Banking 37, 949-955.

Engel, C., 2013. Exchange rates and interest parity, NBER Working Paper 19336. Forthcoming In: Gopinath, G., Helpman, E., Rogoff, K. (Eds.), Handbook of International Economics, vol. 4. North-Holland, Amsterdam.

Gilchrist, S., Saito, M., 2008. Expectations, asset prices, and monetary policy: The role of learning. In Campbell, J.Y. (Ed.), Asset Prices and Monetary Policy. University of Chicago Press, Chicago, pp. 45-100.

Gilles, C., LeRoy, S.F., 1991. Econometric aspects of variance-bounds tests: A survey. Review of Financial Studies 4, 753-791.

Gourinchas, P.-O., Tornell, A., 2004. Exchange rate puzzles and distorted beliefs. Journal of International Economics 64, 303-333.

Grossman, S.J., Shiller, R.J., 1981. The determinants of the variability of stock market prices. American Economic Review, Papers and Proceedings 71, 222-227.

Harvey, A.C., 1993. Time Series Models. MIT Press, Cambridge.

Kleidon, A.W., 1986. Variance bounds tests and stock price valuation models. Journal of Political Economy 94, 953-1001.

Kocherlakota, N.R., 1990. On the discount factor in growth economies. Journal of Monetary Economics 25, 43-47.

Lansing, K.J., 2010. Rational and near-rational bubbles without drift. Economic Journal 120, 1149-1174.

Lansing, K.J., 2014. A note on variance bounds for asset price changes. Federal Reserve Bank of San Francisco, Working Paper 2010-29.

LeRoy, S.F., 1984. Efficiency and the variability of asset prices. American Economic Review, Papers and Proceedings 74, 183-187.

LeRoy, S.F., 2010. Excess volatility tests. In: Durlauf, S.N., Blume, L.E., (Eds.), The New Palgrave Dictionary of Economics, Second Edition, Macmillan, London.

LeRoy, S.F., LaCivita, C.J., 1981. Risk aversion and the dispersion of asset prices. Journal of Business 54, 535-547.

LeRoy, S.F., Parke, W.R., 1992. Stock price volatility: Tests based on the geometric random walk. American Economic Review 82, 981-992.

LeRoy, S.F., Porter, R.D., 1981. The present-value relation: Tests based on implied variance bounds. Econometrica 49, 555-577.

Lucas, R.E., 1978. Asset prices in an exchange economy. Econometrica 46, 1429-1445.

Marsh, T.A., Merton, R.C., 1986. Dividend variability and variance bounds tests for the rationality of stock prices. American Economic Review 76, 483-498. 
Mehra, R., Prescott, E., 1985. The equity premium: a puzzle. Journal of Monetary Economics 14, 145-161.

Otrok, C., Ravikumar, B., Whiteman, C.H., 2002. Habit formation: A resolution of the equity premium puzzle? Journal of Monetary Economics 49, 1261-1288.

Shiller, R.J., 1981. Do stock prices move too much to be justified by subsequent changes in dividends? American Economic Review 71, 421-436.

Shiller, R.J., 2003. From efficient markets theory to behavioral finance. Journal of Economic Perspectives 17 (Winter), 83-104.

Veronesi, P., 2000. How does information quality affect stock returns? Journal of Finance 55, 807-837.

West, K.D., 1988a. Bubbles, fads, and stock price volatility tests: A partial evaluation. Journal of Finance 43, 639-656.

West, K.D., 1988b. Dividend innovations and stock price volatility. Econometrica 56, 37-61. 
Volatility of Log Price-Dividend Ratio

Baseline: $\sigma_{\varepsilon} / \sigma_{v}=2, \rho=0.583$
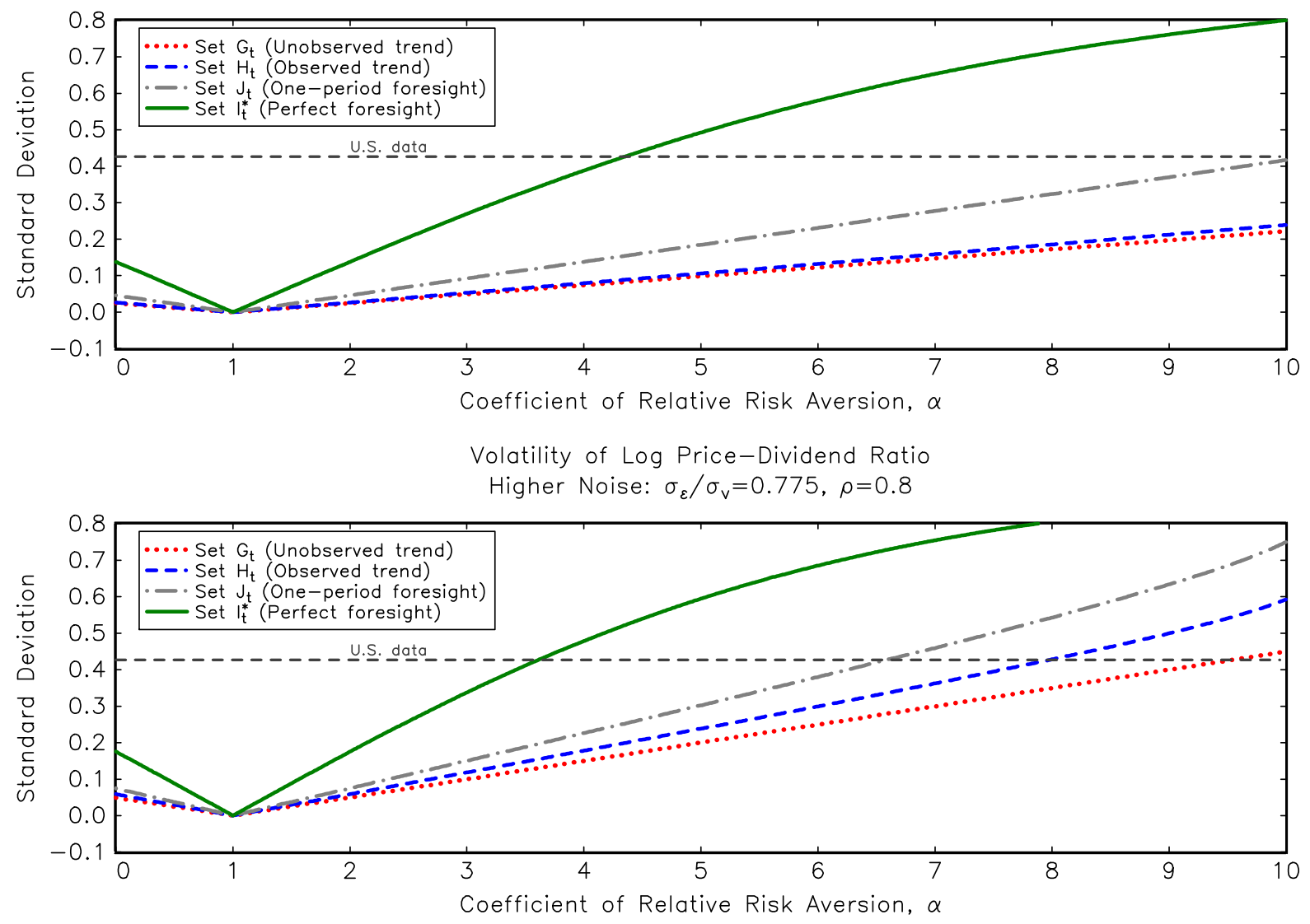

Figure 1: Investor information and the volatility of the log price-dividend ratio. The volatility of the $\log$ price-dividend ratio increases monotonically with investor information about the dividend process. For the baseline calibration (top panel), model-predicted volatility can match the data volatility only when investors are endowed with at least some knowledge about future dividends, i.e., information sets $J_{t}$ or $I_{t}^{*}$. For the higher noise calibration (bottom panel), model-predicted volatility can match the data volatility with $\alpha \leq 10$ under all four information sets. 

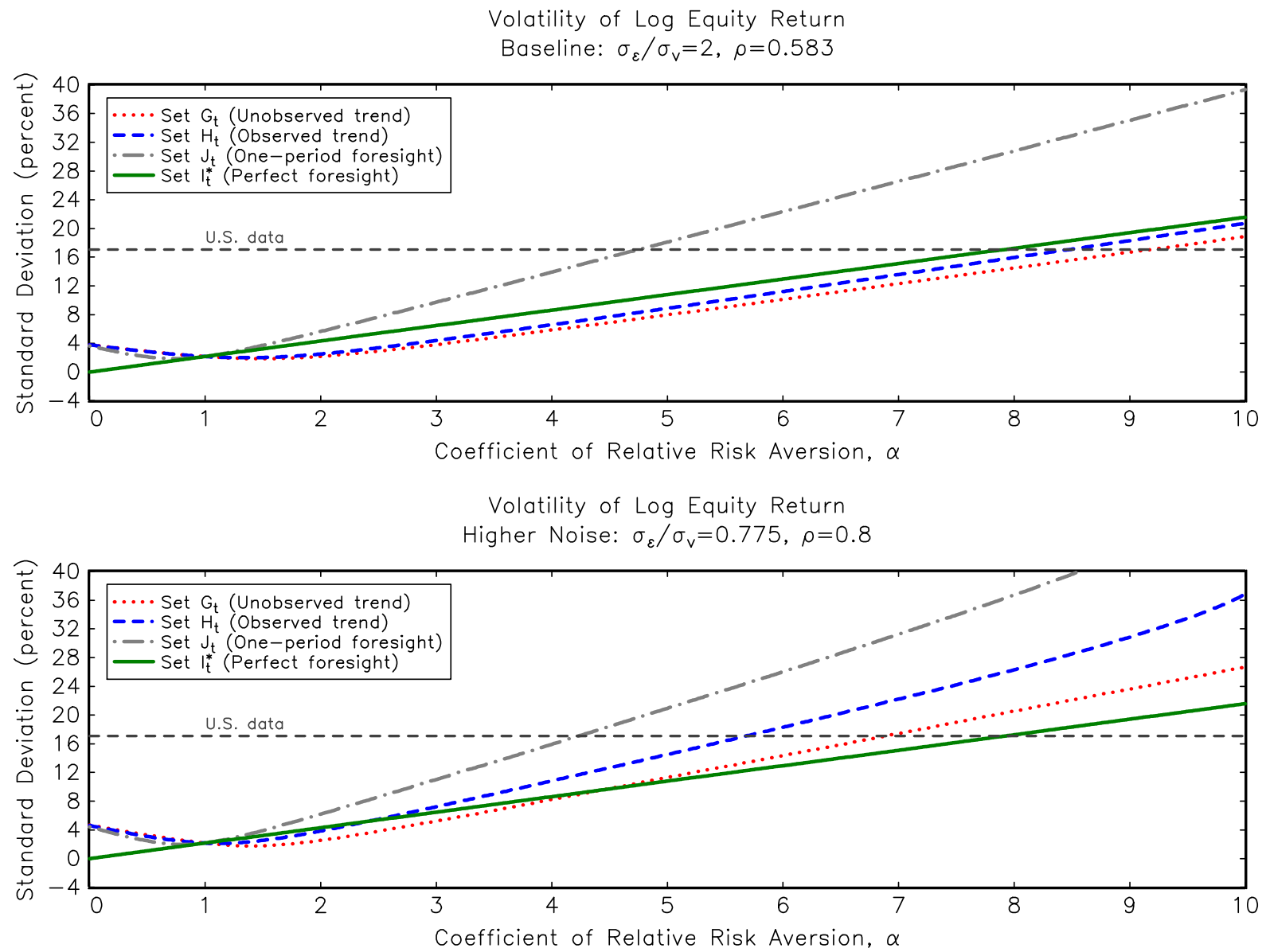

Figure 2: Investor information and the volatility of the log equity return. Providing investors with more information about the dividend process can either increase or decrease the volatility of the log equity return. Moreover, under the higher noise calibration (bottom panel), the volatility lines can cross at two different values of $\alpha$, implying reversals in the variance ordering at the crossing point. For both calibrations, model-predicted volatility can match the data volatility with $\alpha \leq 10$ under all four information sets. 
Volatility of Log Excess Return on Equity

Baseline: $\sigma_{\varepsilon} / \sigma_{v}=2, \rho=0.583$

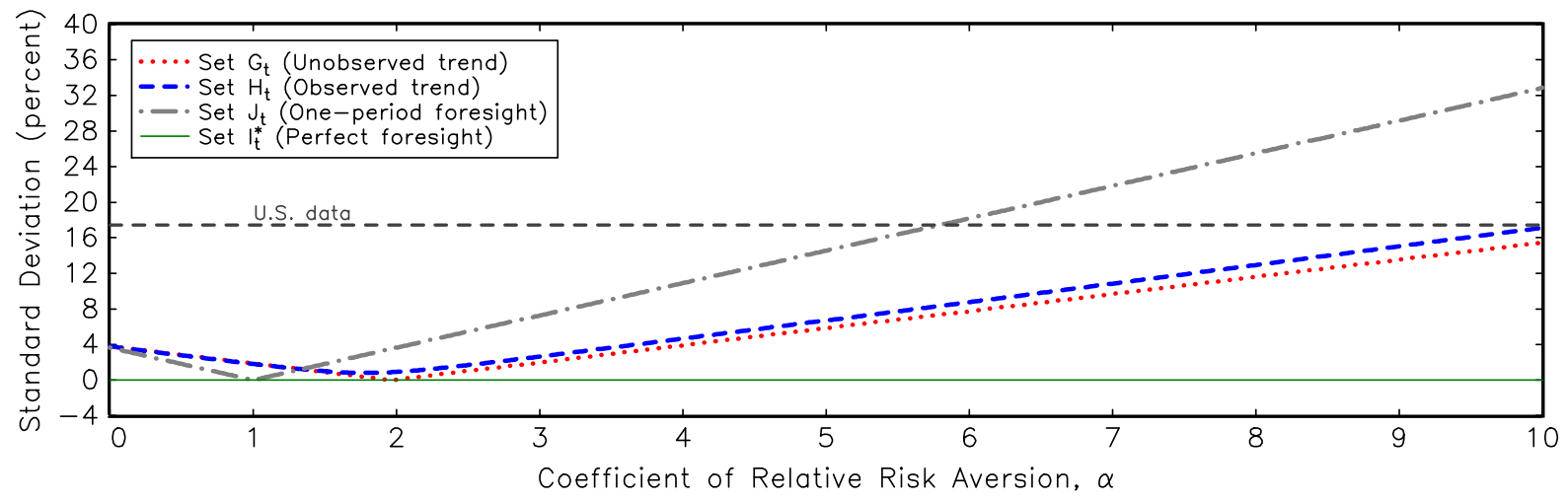

Volatility of Log Excess Return on Equity

Higher Noise: $\sigma_{\varepsilon} / \sigma_{v}=0.775, \rho=0.8$

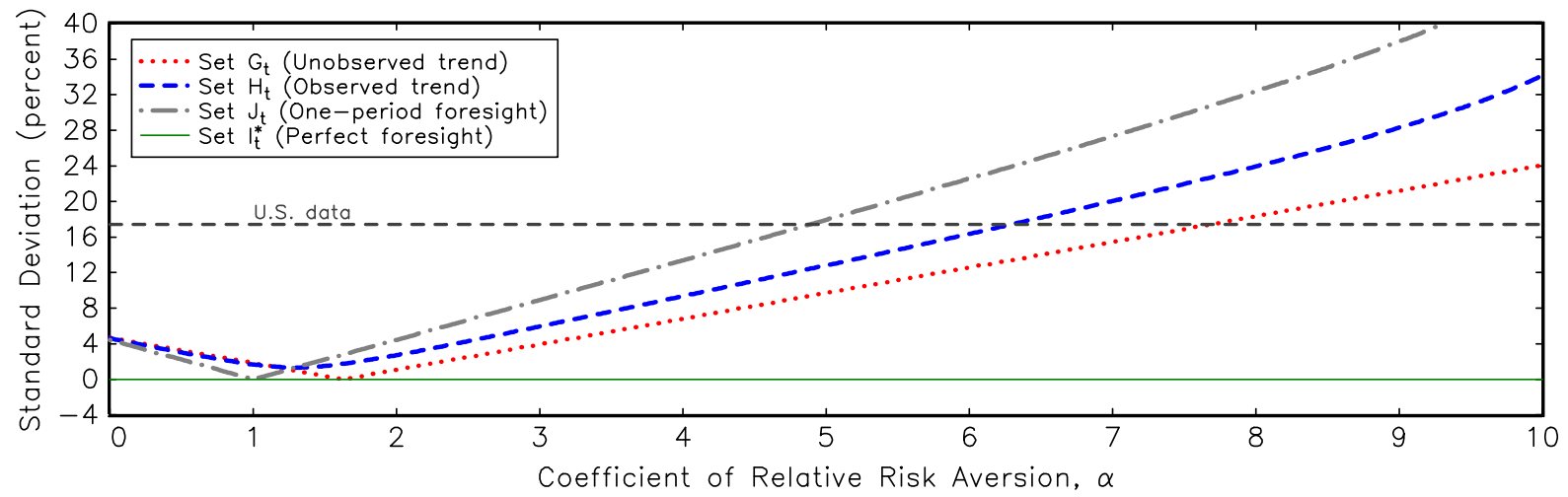

Figure 3: Investor information and the volatility of the log excess return on equity. Providing investors with more information about the dividend process can either increase or decrease the volatility of the log excess return on equity. For the baseline calibration (top panel), model-predicted volatility can match the data volatility with $\alpha \leq 10$ only under information set $J_{t}$. For the higher noise calibration (bottom panel), model-predicted volatility can match the data volatility under information sets $G_{t}, H_{t}$, and $J_{t}$. 

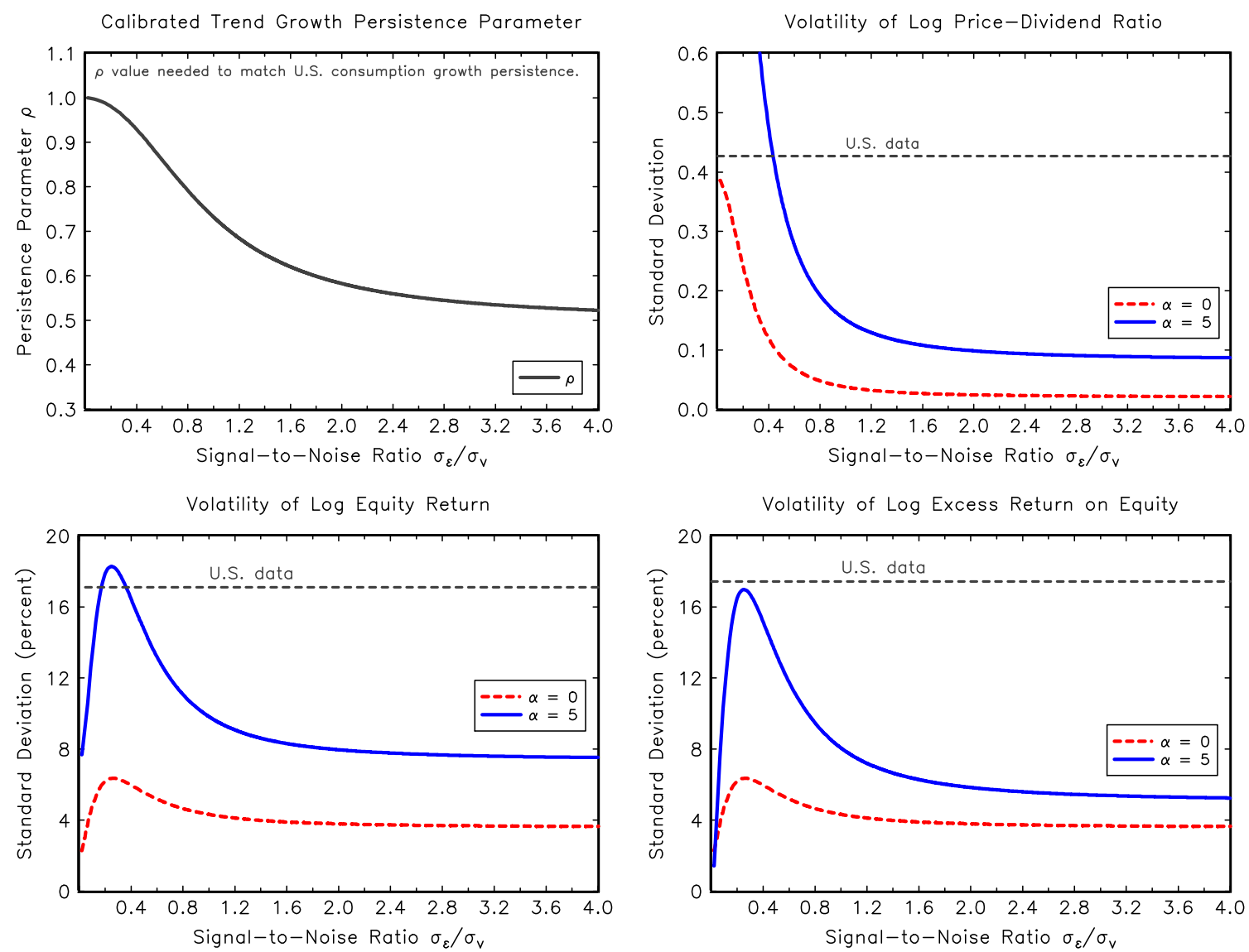

Figure 4: Effects of noise and risk aversion on volatility. For information set $G_{t}$ (unobserved trend growth), the figure shows the effect of changing the target signal-to-noise ratio $\sigma_{\varepsilon} / \sigma_{v}$ while holding $\operatorname{Var}\left(x_{t}\right)$ and $\operatorname{Corr}\left(x_{t}, x_{t-1}\right)$ constant at the U.S. data values shown in Table 2. As $\sigma_{\varepsilon} / \sigma_{v} \rightarrow 0$, the calibration procedure requires $\rho \rightarrow 1$. When $\alpha=5$, the model can approximately match the standard deviations of asset pricing variables in the data when $\sigma_{\varepsilon} / \sigma_{v} \simeq 0.36$ and $\rho \simeq 0.94$ 